\title{
Clinical Evaluation of the Accuracy of Interocclusal Recording Materials
}

\author{
LaDeane Fattore-Bruno \\ Loyola University Chicago
}

Follow this and additional works at: https://ecommons.luc.edu/luc_theses

Part of the Oral Biology and Oral Pathology Commons

\section{Recommended Citation}

Fattore-Bruno, LaDeane, "Clinical Evaluation of the Accuracy of Interocclusal Recording Materials" (1979). Master's Theses. 3026.

https://ecommons.luc.edu/luc_theses/3026

This Thesis is brought to you for free and open access by the Theses and Dissertations at Loyola eCommons. It has been accepted for inclusion in Master's Theses by an authorized administrator of Loyola eCommons. For more information, please contact ecommons@luc.edu. (c) $($ ) $\Theta \Theta$

This work is licensed under a Creative Commons Attribution-Noncommercial-No Derivative Works 3.0 License. Copyright (c) 1979 LaDeane Fattore-Bruno 


\section{CLINICAL EVALUATION OF THE ACCURACY \\ OF INTEROCCLUSAL RECORDING MATERIALS}

By

LaDeane Fattore-Bruno, B.S., D.D.S.

A Thesis Submitted to the Faculty of the Graduate School of Loyola University in Partial Fulfillment of the Requirements for the Degree of Master of Science Apri1, 1979 


\section{ACKNOWLEDGEMENTS}

The author wishes to acknowledge the following people:

The Junior and Senior dental students and staff who volunteered their time for this study.

Doctor Timothy Hart for his willing assistance in the statistical analysis of this research.

My husband, Doctor James Bruno, for his moral support.

The members of my committee, Doctor William F.P. Malone, Doctor Boleslaw Mazur, and Doctor James L. Sandrik.

Special gratitude goes to Doctor Malone for his instruction, guidance, and patience. 


\section{VITAE}

LaDeane Fattore-Bruno was born in Chicago, Illinois, on March 8, 1950. She attended Willow Springs School and Argo Community High School in Argo-Summit, Illinois.

She received a Bachelor of Science degree in June, 1973, from Loyola University, Chicago, I11inois.

A Doctor of Dental Surgery degree was conferred upon her by Loyola University Dental School, 1977.

In July, 1977, she entered graduate school at Loyola University to pursue a specialty in Fixed Prosthodontics and a Master of Science degree in Oral Biology.

From June 1978, to May, 1979, she was a Clinical Instructor in the Undergraduate Department of Fixed Prosthodontics at Loyola University School of Dentistry. 
TABLE OF CONTENTS

ACKNOWLEDGEMENTS ................ ii

$\operatorname{VITAE} \ldots \ldots \ldots \ldots \ldots \ldots \ldots \ldots \ldots \ldots \ldots \ldots \ldots$

TABLE OF CONTENTS............... iv

LIST OF TABLES................. vi

LIST OF ILLUSTRATIONS............. vii

CONTENTS OF THE APPENDIX........... viii

I INTRODUCTION .................. 1

II REVIEW OF THE LITERATURE........... 5

Centric Relation................... 5

Centric Relation and Vertical Dimension... 6

How Reproducible is Centric Relation?.... 8

Causes of Error in Recording Centric

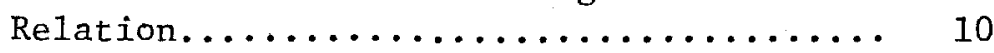

Centric Occlusion................. 12

Centric Occlusion in Swallowing and

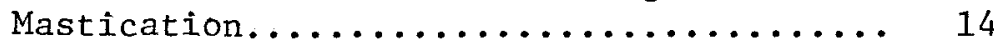

Centric Occlusion and Rehabilitation..... 16

Characteristics of an Ideal Interocclusal

Bite Medium...................... 18

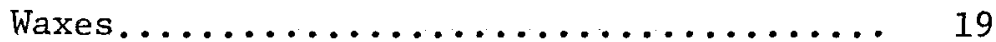

ZOE........................... 20

Potential Sources of Error in Recording

Centric Position.................. 22

Polyether as an Interocclusal Record..... 25

Summary of the Review of Literature...... 27

III METHODS AND MATERIALS............ 30

IV EXPERIMENTAL RESULTS............. 41 
DISCUSSION..................... 54

Limitation of Study............. 58

Comparison of Results to

Literature and Its Clinical.

Implications................ 60

Clinical Significance of Study...... 61

Future Studies................ 62

BIBLIOGRAPHY................. 64

APPENDIX.................. 67 


\section{LIST OF TABLES}

TABLE

PAGE

1 Means and Standard Deviations of

Four Interocclusal Records .......... 41

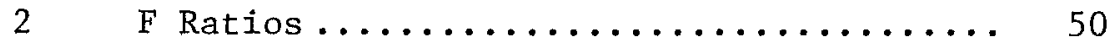




\section{LIST OF ILLUSTRATIONS}

\section{FIGURE}

1 Zinc Oxide and Eugenol Paste with

Coe Tray Carrier................... 35

2 Reinforced Wax and Pink Baseplate Wax..... 36

3 Coe Bite Registration Trays ............ 37

4 Polyether Interocclusal Recording Medium.... 38

5 Buhnergraph Mounted on Whip Mix Articulator. 39

6 Recording Position of Mandibular Cast...... 39

$7 \quad$ Patient Record.................... 40

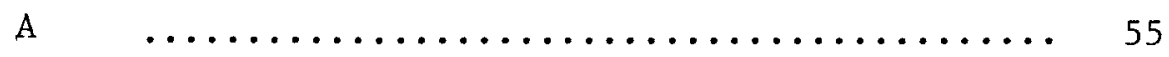

B Declanation.................... 56

C Rotation.................... 57

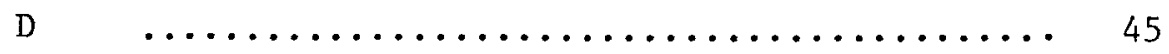

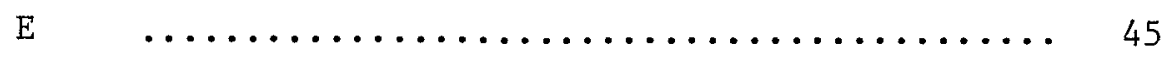

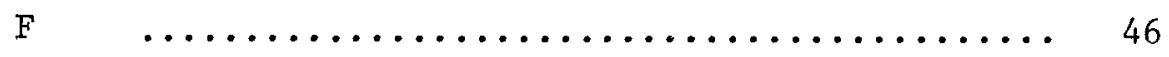

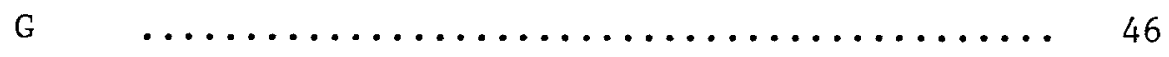

$\mathrm{H} \quad \ldots \ldots \ldots \ldots \ldots \ldots \ldots \ldots \ldots \ldots \ldots \ldots \ldots \ldots \ldots \ldots$ 
CONTENTS OF THE APPENDIX

PAGE

Rotation and Declanation in Degrees and the $X$ and $Y$ Movement of the Center of the Articulator Hinge Axis in Millimeters.... 68

Angles Formed by Intersection of Lines $\mathrm{CO}-\mathrm{CO}^{\prime}$ and the Frankfort Horizontal Plane.... 73

Measurement of Line $\mathrm{CO}-\mathrm{CO}^{\prime} \ldots \ldots \ldots \ldots \ldots \ldots$ 
CHAPTER I

\section{INTRODUCTION}

When dentists establish a patient's occlusion by restorative procedures, they develop an occlusal relationship congruent with the concept of an "ideal" or "optimal condyle-fossa" relationship. However, a great deal of controversy exists over the location of this "ideal" condyle position and how to attain it.

Even if there were general agreement to an "optimum condyle position," dentists would still be faced with the problem of recording and transferring it to an articulator. This critical transfer, which can be one of the weakest links in a painstaking technique, is frequent1y accomplished with some type of interocclusal record.

Wax has achieved wide acceptance for this precise transfer. However, its inherent nature constituted an opportunity for error (Nagle, 1959). Dental waxes can be hard, soft, thick or thin, heated or chilled throughout its bulk without uniformity. (Berman, 1960). A wax record is subjected to being scraped, blunted, distorted, and compressed. Complete closure into waxes was not achievable under pressures comparable to those of a clinical setting (Millstein, Clark, Kronman, 1973).

No wax permitted the complete seating of casts (Shanahan and Leff, 1960). Waxes incorrectly registered the incisal and occlusal forms of teeth (Tylman, 1978). Wax caused patients to close into 
undesirable patterns. Wax had the tendency to move teeth into abnormal positions.

Zinc oxide and eugenol paste was felt by some researchers and clinicians to be the material of choice for interocclusal records (Berman, 1960; Sindledecker, 1978; Tylman, 1978). The material had true fluidity, offered no resistance to closure, set to a hard, noncompressible consistency and was sharp and easily read (Berman, 1960). Casts were articulated accurately without fear of distortion or compression of the record unequally in the vertical dimension (Berman, 1960). ZOE very accurately reproduced the incisal or occlusal form of teeth. It remained rigid with little or no dimensional change after setting. It can be easily reassembled if the record was broken or damaged in any way.

However, ZOE cannot be modified, corrected, or verified with comparative ease. This material, once set, was irreversible. Only minor changes can be accomplished. Final accuracy must be assumed without verification. This assumption was very often incorrect (Wirth and Aplin, 1971).

ZOE had other difficulties. It had a relatively long setting time in which registration errors were introduced. The details of the teeth on the record reproduced surpassed the detail on many casts. ZOE had the tendency to fracture or stick to the teeth (Wirth and Ap1in, 1971). This lead to unseen distortion of the record upon its removal from the teeth or through its trimming to 
allow casts to seat completely.

Ramitec, a new polyether interocclusal recording material, is proving to be as useful as its impression material counterpart. This elastomeric compound was made from polyethers terminated with amino groups which are cross-linked with strong acids such as aromatic sulfonic acid esthers.

This cross-linked rubber was reported to have high dimensional accuracy after polymerization and storage (JADA, 1977). When compared to other elastomeres, it was reported to possess the highest recovery after deformation and the least dimensional change following removal from the mouth.

Polyether Chemical Formula:<smiles>CCC(OC(=O)CO)N(C)C</smiles>

The purpose of this study was to determine the accuracy of four materials commonly used for recording interocclusal relationships. Thirty-one subjects age twenty-five to thirty with a full complement of teeth were selected to participate. There were seventeen females and fourteen males used in this study.

Maxillary casts of each patient were mounted on an arcon articulator with a face bow. Mandibular casts were mounted in maximum intercuspal position. A Buhnergraph with bilateral recording devices 
attached to the condylar assembly of the articulator was used to record and evaluate the accuracy of the four materials. Any measurement which deviated from the pre-established centric occlusion position in a vertical, antero-posterior and declanation-rotational direction was recorded. The resultant numerical deviations were subjected to a statistical analysis of variance. 


\section{CHAPTER II}

\section{REVIEW OF THE LITERATURE}

\section{CENTRIC RELATION}

It has been considered essential to certain clinicians and authors to distinguish between the terminal hinge and the habitual automatic opening and closing movement. Beyron (1969) stated the terminal hinge movement was the posterior opening and closing movement carried out with the mandible retruded. He believed the position after terminal hinge closure was the retruded contact position or centric jaw relation. The joint structures and their ligaments together with passive muscle resistance were believed by many investigators to be the determiners of centric jaw relation (Sicher, 1965; Arstadt, 1954; Zola, 1963; Boucher and Jacoby, 1961; Brotman, 1960).

The retruded contact position was purported to be reproducible and may be recorded with a predictable percentage of accuracy. It was believed to be the position where the condyles can be stationarily seated in both joints simultaneously. Many investigators thought centric relation was an excellent reference position. They believed it can accurately evaluate maxillomandibular relationships (Beyron, 1969; Granger, 1963; Stuart and Stallard, 1960).

However, centric relation was surrounded by controversy starting with the very definition of it. Sears (1960) stated that in 1950 when the Committee on Principles, Concepts, and Practices of the Academy of Denture Prosthetics tried to formulate statements dealing 
with centric jaw relation, they found they all had different interpretations of the definition in the Academy's Glossary of Prosthodontic Terms. In that same year Sicher wrote, "Where, then, do we stand today in the controversy over the jaw relations in centric position? I think it would be best to reserve judgment and to consider 'centric' or 'ideal' or 'harmonious' mandibular position as the definition of a problem rather than of a solution." Sicher was prophetic. Current dental 1iterature still showed a lack of agreement in the use of terms for jaw relations and associated concepts.

\section{CENTRIC RELATION AND VERTICAL DIMENSION}

Granger (1963) stated a centric interocclusal record involved the use of a material in the mouth upon which the patient would bite with his own muscular force, while he maintained the hinge axis in its posterior terminal position. The proprioceptive mechanism necessitated a bite made at an increased vertical dimension with a minimum of closing pressure. The "bite" had to be made with a pure rotary closure. It was then mounted on the hinge axis. Here the cast was closed to the correct vertical relation to the maxilla.

Cohen (1960) and Brotman (1960) also agreed centric relation could be taken at an increased vertical dimension. According to Brotman, all true hinge-axis records, no matter how thick, fit properly between two casts if the mounting was accurate and if the axis was located properly. Vertical dimension could be altered as much as 3 or $4 \mathrm{~mm}$ between the mounting of the casts. 
According to Coulourites (1955), however, the correct centric relation depended upon the correct vertical dimension. John Ulrich (1959) did a study with 3 subjects where he asked them to hold the mandible back while opening maximally. Two of the individuals could not suppress the forward movements of the condyles. The third individual did carry out an opening movement but to only half of its extent without any significant forward glide of the condyles.

Shanahan and Leff (1966) advised against the change of vertical dimension of occlusion on a hinge articulator because it was physiologically inaccurate. Thick wax interocclusal records were used to mount casts on the instrument because deflective occlusal contacts were believed to direct the mandible from the correct centric relation.

Centric relation has been defined as the most retruded position of the condyles from which free lateral movements can be made at a given vertical dimension. Standard and Lepley (1955) found nothing wrong with this definition provided dentists accepted the concept that with every change in vertical dimension, there was a different centric relation. They proposed what they believed was a better definition: "The balanced position of the condyles from which free lateral movements can be made when the mandible is in physiologic rest position." 
HOW REPRODUCIBLE IS CENTRIC RELATION?

Wood (1968) didn't believe maxillomandibular relations were fixed mechanical entities in the living skull. He believed they were only as stable as the living tissues of everchanging patients. Centric relation did not necessarily represent the most physiologic relation of the tissues involved. Wood believed a prosthodontist could not be dogmatic about the registration. If he seriously worked with a patient, the results obtained were their mutual best effort. Different dentists could possibly select different "centers" but the possibility of a usable and practical center would not be nullified. The right and left centers of rotation were to be considered the day's recording. In another week, the points of pure rotation may have moved.

Wood (1968) stated the experienced dentist may have used his special technique and personal magic to minimize the many hazards of recording centric relation but if the patient's mandible did not function there, his effort failed.

Schireson (1963) also did not believe in the immutability of centric relation. Maxillomandibular relations changed bringing with them changes in the occlusal relations, force patterns, and habit patterns of the teeth. He cited tests with templates in the form of maxillomandibular acrylic resin immobilizing splints where centric relation changed appreciably within a few weeks. These tests were made with the use of the most posterior clinical position of the mandible as the point of reference. 
According to Brotman (1960) it wasn't clear whether or not the hinge axis position was the proper maxillomandibular relationship. The arch relationship didn't always exist in mouths with natural, healthy dentitions. Yet, for many years, fixed occlusal restorations were built with the mandible in centric relation and the restorations worked satisfactorily. He lamely concluded the hinge axis is a physiologically acceptable maxillomandibular relationship.

Moyers (1956) discussed centric relation reproducibility in terms of growth and the neuromuscular complex. During growth of the craniofacial complex of bones, centric relation must change, for the mandible grows at a faster rate downward and forward than do the maxillae. Centric relation was not the same when the patient was tense and tired as when he was freshened and relaxed. It was different when he was afraid than when quiet and at ease. Since centric relation is a neurological concept, Moyers felt the reflexes controlling centric relation must be learned and be capable of learning. Both the postural position (centric occlusion) and centric relation became relatively more stable with age, but the concept of a fixed and immutable centric relation was contrary to all that is known of neuromuscular physiology.

Moyers (1956) pointed out that neuromuscular reflexes were unique to the patient, not the dentist. The position of the mandible of any patient was determined by the patient's neuromuscular mechanisms and not by the dentist's "paraphenalia". Centric relation was 
not determined by the dentist's wishes. Jaw relations were registered by the patient. Moyers said any successful technique worked, not because of the ingenuity of the engineering involved, but because of adherence to physiologic guidelines.

According to Moyers there was a lack of convincing evidence the most retruded position of the condyles from which lateral movements may be made coincides in all patients with centric relation, except by definition. His experiments have shown that $76 \%$ of the subjects observed demonstrated muscle imbalance and straining when the jaws were closed with the condyles in their most retruded positions. His data had been obtained from some 1,000 observations taken electromyographically. In edentulous patients, only $32 \%$ had shown muscle relaxation and balance when the condyles were in their most retruded position. Moyers' data supported well the laminographic work of Rickets. In Moyers' opinion, the greater the occlusal disharmony, the more likely centric relation is to be found somewhere other than in the most retruded position, simply because greater joint mobility developed with eccentric occlusions.

\section{CAUSES OF ERROR IN RECORDING CENTRIC RELATION}

Kingery (1959) grouped sources of error into two categories: technical and those of patient origin.

TECHNICAL CAUSES OF ERROR included poorly adapted registration bases, carelessness in assembling the record on an occluding frame, displacement of the recording bases by the dentist in attempting 
to force the mandible into its terminal position, excessive closing pressure by the patient, and the use of too-resistant recording medium.

ERRORS OF PATIENT ORIGIN included those caused by tensions, habits, moods of the patient and the influence of the dentist's attitude.

G. Newel1 Wood (1968) said the location of an individual patient's mandibular hinge position was a human effort requiring both cooperation and coordination between the dentist and his patient. The muscles that move the mandible must be completely relaxed. The patient or the patient with the dentist's gentle guidance, may retrude the mandible and arc the jaw in a true hinge position. However, the range of pure arcing without translation was limited to approximately $15^{\circ}$. According to Wood, if the dentist-patient team coordinated and if the operator persevered within the narrow arcing range, the centric relation position could be found.

An accurate jaw position required a motor act which was the result of proprioceptor impulses originating anywhere in the masticatory mechanism, or even from outside of the mechanism. Where periodontal proprioception was lost (as when teeth are lost), motor activity may be influenced even more by touch, pressure, and other painful stimuli arising from closure on the denture base (Berman, 1960)

Guichet (1977) pointed out occlusal contact patterns programmed 
adaptive muscle responses. In the same manner, any medium placed between the teeth generated proprioceptive signals and adaptive muscle responses. Attempts by the dentist to manipulate the patient's condyles into centric relation may be strongly hindered when the patient's musculature reacted in a protective reflex action.

Granger (1963) stated there were many techniques for obtaining a centric relation record, equally good in the hands of various dentists. However, a full occlusal restoration made with a correct centric relation record was rarely seen. Therefore, a technique was not of much value without an understanding of what was required. The purpose of a centric relation record was not merely to record a retruded relation of the mandible. The most important part of this record was to elevate the condyles out of their rest positions and up to their functioning fulcral positions.

\section{CENTRIC OCCLUSION}

The habitua1, automatic opening and closing movement-rapid closure from open position was carried out within the total envelope of motion. Thus it had been considered an intraborder movement. Repeated habitual closing movements vary slightly, but the last part of the movement into the occlusal position was remarkably stable. Regulation was accomplished by past and present muscle memories. The position after closure was the intercuspal position or maximum intercuspation of opposing teeth. This position was commonly called centric occlusion (Beyron, 1969). 
In a smoothly functioning system the habitual, automatic opening and closing movement was performed with well-synchronized muscular action. The intercuspal position attained after such a closure was a stable contact position. However, the automatic closure can be altered by various interferences in occlusion. This position was then considered unreliable for evaluation of the maxillomandibular relationships (Beyron, 1969).

Beyron (1964) examined adolescent and adult primitive people, Australian aborigines, with practically complete dental arches and morphologically acceptable occlusion. In all his studies, most of the subjects were found to have an anteroposterior distance between the retruded contact position and the intercuspal position. As a rule, it was in only 10 percent of the subjects that the intercuspal position coincided with the retruded position of the mandible. On an average, the distance between the two positions was found to be about $1 \mathrm{~mm}$ (with a variation of 0 to $2 \mathrm{~mm}$ ). Similar values of about the same magnitude have also been reported for children. From these morphologic studies it may be concluded maximum intercuspation normally occurred anterior to the retruded contact position at a varying but short distance.

It is often stated maximum intercuspation should coincide with the retruded contact position. The reproducibility of the retruded contact position and the accuracy with which it can be obtained was however, no proof it was the physiologically optimal maxillomandibular 
relation. Maximum intercuspation was a maxillomandibular relation with a small range anterior to the retruded contact position that must be considered physiologically normal (Beyron, 1969).

Posselt (1958) had shown in his study the habitual closing position to be from 1.0 to $1.4 \mathrm{~mm}$ anterior to the most retruded or axis position.

\section{CENTRIC OCCLUSION IN SWALLOWING AND MASTICATION}

In 1953 Jankelson, Hoffman and Hendron did a cineflourographic study on mastication. They found centric occlusion to be the only tooth contact of any significance occuring during stomatognathic function. Evidence of eccentric tooth balance during eating was not found.

In 1961 Jerome Schweitzer performed some research studies on masticatory function in man. He found the posterior borderline or hinge closure did not seem to be reached in functional chewing in the sagittal plane. In power closure both condyles should have been in the hinge position when the mandible reached the level of intercuspation. In some theories of occlusion the mandible followed the posterior border path during power closure. This occurred infrequently in Schweitzer's research.

In June, 1967, at the Tufts Berkshire Conference, Pameijer, Glickman and Roeber reported the following: "Centric relation does not seem to be an important functional position in swallowing or chewing. Of 477 chewing contacts studied in the sagittal plane, 
only 7 occurred with the mandible in habitual occlusion or anterior to it. The so-called 'habitual occlusion' is really the working occlusion since it is the position in which tooth contact occurs most often in chewing and swallowing." They also found, as Schweitzer did in 1961, only 4 of 30 swallowing contacts made with the transmitter registering in the sagittal plane occurred in centric relation.

In a subsequent study they reported by guided closure and by instruction, it was possible to register tooth contacts in the most retruded position of the mandible. However, this position was used relatively infrequently in eating and swallowing. Most contacts during chewing occurred in habitual occlusion. The few tooth contacts during chewing posterior to habitual occlusion were recorded both during chewing and swallowing. In most instances the teeth contacted in habitual occlusion during swallowing or a retrusive glide occurred from an anterior position into habitual occlusion.

Besides the findings of Schweitzer and Glickman, there were others who have demonstrated power closure of the mandible did not occur in the most retruded position of the condyle. Among them were Higley and Logan ( 1960), Janke1son (1973), and Shanahan and Leff (1966).

There was the implication that if centric occlusion did not coincide with centric relation, the patient had disharmonies and was therefore, predisposed to periodontal disease. From the studies mentioned and those of Posselt (1962), Weinberg (1964), Ricketts (1950) 
and Frisch (1966), the indication was that, in most patients examined, centric occlusion did not coincide with centric relation. Therefore, the close relationship between occlusal disharmonies, occlusal trauma, and periodontal disease was, at the very least, open to serious doubt.

\section{CENTRIC OCCLUSION AND REHABILITATION}

Douglas Lyon (1960) stated centric relation was the most important concern in occlusal rehabilitation and, if a satisfactory, tolerated and functional centric occlusion was present, there was no need to destroy the relationship. The dentist would then have to resort to some arbitrary method to re-establish this relationship. Unsuccessful results in occlusal rehabilitation had not been caused by the use of, or failure to use a specific instrument, hinge axis, recording, or any other registration. Faulty diagnosis was generally the cause of unsuccessful results. Many dentists failed to take into consideration some occlusions were best left alone, others should be treated conservatively, and others gave best results when duplicated in a harmonious functional occlusion.

Strohaver (1972) stated when an occlusion must be reconstructed on an articulator without benefit of centric occlusion, some other repeatable reference relationship was necessary. Centric relation was considered to be the only other repeatable reference relationship with which to coordinate the occlusion. Although it has been stated no other phase of dentistry was so important as a clear understanding of centric relation, this relationship continued to mean different 
things to different people. Definitions of centric relation were so numerous and varied this term was practically useless unless it was accompanied by the user's definition.

Brecker (1959) in a classic article stated many natural dentitions requiring rehabilitation possessed a satisfactory, tolerant and functional centric occlusion. This position was the most important concern of occlusal rehabilitation. There was no need to destroy the position and then resort to the arbitrary method employed for complete dentures to restore the relationship. Once the tolerated and correct vertical dimension of occlusion was lost or destroyed, it is almost impossible to record the correct one again. The sooner the treatment of occlusion in dentitions was separated from that used in complete dentures, the more conservative and the more successful will be the rehabilitation.

\section{METHODS USED TO RECORD CENTRIC JAW POSITION}

When dentists attempted to re-establish a patient's occlusion by restorative procedures, they must develop a new occlusal relationship coinciding with their concept of an "ideal" or "optimal" condylefossa relationship. However, much controversy existed over the location of this "ideal" condyle position and how to establish it (Lundeen, 1974).

Even if there were general agreement about the definition of centric relation, dentists would still be faced with the problem of recording and transferring it to an articulator (Lundeen, 1974; 
Strohaver, 1972). This critical transfer, which can be one of the weakest links in a painstaking technique, was frequently accomplished with some type of interocclusal record. Attaining an accurate centric relation record had been called the most important single step in the construction of any prosthesis. Despite the importance attributed to this procedure, there was a wide divergence of opinion concerning the methods and materials to be used for the recording (Strohaver, 1972)

\section{CHARACTERISTICS OF AN IDEAL INTEROCCLUSAL BITE MEDIUM}

The general requirements of an ideal material used in the registration of interocclusal records are: 1) Material which did not displace the teeth during intercuspation; 2) Exhibited little or no dimensional change upon setting; 3) Accurately recorded the occlusal and incisal surfaces of the teeth; 4) Remained rigid after setting; 5) Minimal resistance form so it did not affect the normal closing pattern of the mandible or caused abnormal movement of the teeth during closure (Pipia, 1978; Berman, 1960). Silverman (1957) stated an interocclusal record should offer no resistance to closure, have fluidity, and permit the masticatory mechanism to operate free from strain. An accurate centric relation can be obtained only with minimal closing force. Any attempt to make a record with anything more than minimal closing force generally leads to an incorrect centric relation. 6) Material had the capacity and ease of verification; 7) Ease of use and modification; 8) Material caused no 
adverse effects on tissues involved in the recording (Wirth and Ap1in, 1971).

For a high degree of accuracy, all interocclusal records should be checked several times in the patient's mouth. More than one record may be desired or even necessary (Kingery, 1959; Brotman, 1960; Sindledecker, 1978; Tylman, 1978).

\section{WAXES}

Restorative procedures require the transfer of tooth and jaw relationships to some form of an articulator. Wax had achieved wide acceptance for this precise transfer despite the fact its inherent nature constituted an opportunity for error (Nagle, 1959). While wax was a versatile material, it's far from the perfect medium for the registration of the critical interocclusal record (Berman, 1960). Berman's study (1960) showed dental waxes could be hard, soft, thick or thin, heated or chilled throughout its bulk without uniformity. Once the record was made, it was subject to being scraped, blunted, distorted and compressed. The softest wax required a weight load of 102 grams for full penetration, while the hardest wax required 357 grams.

Shanahan and Leff (1960) studied baseplate and impression wax. They found neither wax made a satisfactory interocclusal record for mounting casts on an articulator. As interocclusal bite registration media these waxes rendered only approximate accuracy. Neither wax permitted the complete seating of the casts. 
Millstein, Clark, and Kronman (1973) studied the accuracy of two brands of baseplate wax by varying thickness, initial heating temperature, and closing pressures. The wax records were subjected to varying storage environments, time intervals, and seating pressures. A factorial experimental design for the investigation of the main and interactive effects of these variables was used. The important findings were: 1) Complete closure into the waxes was not achievable under pressures comparable to those of a clinical setting; 2) Storage of wax records in water produced the greatest change in dimension while air cooling produced the least; 3) Considerable vertical and rotational changes occurred when the test model was replaced in a previously formed wax registration; and 4) Exact reproduction of the oxiginal wax recordings was never achieved.

Tylman (1978) stated waxes have distinct disadvantages when used as interocclusal recording material. They do not accurately reproduce the incisal and occlusal forms of the teeth. Wax tended to spread laterally as the teeth close into the material, thus incorrectly registering the occlusal or incisal form. Waxes had considerable dimensional change caused by any fluctuation in temperature. Further, the texture and nature of the wax material tended to cause a patient to close in an undesirable pattern. Wax also had the tendency to move the teeth into abnormal positions.

Wirth and Aplin (1971) classified interocclusal records into 
two categories: Chemical setting (ZOE paste, Nogenol, plaster, Ramitec, etc.) or Thermoplastic waxes.

Berman (1960) felt that plaster, although it could readily flow, was not a great chemical setting interocclusal record. It had to be mixed thinly, lacked adherence, and broke easily. This breakage often caused vital parts of the record to be lost.

Berman (1960) felt ZOE paste was the material of choice for an interocclusal record. The material mixes to a 1) true fluidity, 2) offers no resistance to closure, 3) adheres to its carrier, 4) sets to a hard, noncompressible consistency, 5) is sharp and easily read, and 6) articulation of casts can be accomplished accurately without fear of distortion or compression of the record unequally in the vertical dimension.

Tylman (1978) stated the zinc oxide and eugenol washes came closest to meeting all the requirements of an ideal material to be used for interocclusal records. It accurately reproduced the incisal and occlusal form of teeth. It remained rigid with little or no dimensional change after setting. It is a material that can be easily reassembled if the interocclusal record is broken or damaged in any way.

Strohaver (1972) did a study comparing the accuracy of articulator mountings utilizing various interocclusal records. He found zinc oxide and eugenol paste with a "Lucia jig" produced the least variable group of articulator mountings made with interocclusal 
records.

Wirth and Aplin (1971), however, had some reservations about the properties of the so-called "chemical-setting" records. They felt wax could be modified, changed, corrected, and verified with comparative ease. Materials like ZOE paste and plaster, once set, were irreversible. They could not be modified. Consequently, once the record was made and removed from the mouth, only minor changes, such as trimming, were permitted. Final accuracy had to be assumed without verification. Too often this assumption was incorrect and the need to make it represented a serious deficiency.

Wirth and Aplin (1971) mentioned additional difficulties with such materials: 1) The lengthy setting time in which registration errors can be introduced; 2) The tendency to fracture or stick to the teeth; 3) The details of the teeth on the record reproduced may surpass the detail on many casts. This can lead to unseen distortion of the record upon its removal from the teeth or through its trimming to allow casts to set completely.

\section{POTENTIAL SOURCES OF ERROR IN RECORDING CENTRIC POSITION}

According to Strohaver (1972) the biologic variability of the anatomic hinge cannot be overcome resulting in many potential sources of error in recording and transferring centric position to an articu1ator. It was clinically impractical to construct clutches, locate the hinge axis, make multiple interocclusal records, use a fully adjustable articulator, and split - cast mounting procedure for every 
patient. More arbitrary techniques, in the hands of careful dentists, produced clinical results within the adaptive range of most patients.

Osborne (1969) stated when only a small number of artificial teeth were required, the hand articulation method was indicated. When large numbers of teeth have to be replaced, it was necessary to use some form of adjustable articulator. No articulator, however, can or will reproduce mandibular movements with 100 percent accuracy. Consequently, no articulator more complex than a Hanau $H$ or Dentatus need be employed. Such instruments reproduced the general pattern of movement of the patient, but final adjustment of occlusion must always be carried out in the mouth.

In his study on articulator mountings using interocclusal records, Strohaver (1972) discovered the least variable of ALL methods for mounting the mandibular cast was the hand articulation technique using centric occlusion.

However, Carl Boucher (1972) took issue with Strohaver's study. He said the reason hand articulation turned out to be the most accurately repeatable technique was due to the variable of jaw separation. Centric relation was accurate only at the rest vertical dimension. Centric relation was accurate only at the rest vertical dimension. Boucher felt the vertical dimension variable was wellcontrolled with hand articulation but not with the interocclusal recording media techniques. Boucher did state, however, that even though centric relation was the most constant jaw relation, it is 
difficult to record with repeatable accuracy.

Clinical variables, which were more difficult to control than technique variables, were those which had to do with physical deformation of the anatomic parts being related. There were two rather significant variables to be included in this category (Douglass, 1975).

The first was the physical deformation of the mandible during eccentric or opening movements. The second was the physical displacement of teeth under an occlusal load (Douglass, 1975).

In order to significantly control mandibular distortion, a technique must register arch form at or near the vertical dimension of occlusion (Douglass, 1975). DeMarco and Paine (1974) found distortion to be quite negligible up to 28 percent of maximal opening. Techniques requiring impressions made at a vertical opening of the jaws, such as the opposing ful1-arch techniques, were subject to error if the mandible was beyond 28 percent of maximum opening. This was also true, although not to as significant a degree, for those techniques utilizing quadrant casts made with the jaws in an open position (DeMarco and Paine, 1974).

In terms of establishing centric occlusion, the second variable was probably more significant than the first. Goto (1971) found shifting of the teeth occurred when the dentition assumed a maximal interdigitation. Therefore, casts made of teeth resting in unstrained periodontal membranes cannot be placed in maximal inter- 
digitation. The centric occlusion seen in the mounted full-arch casts was not the same as the centric occlusion the patient was able to attain. Cast restorations made to this incorrect centric occlusion may, therefore, feel "high" at the clinical try-in.

The physical displacement of teeth in occlusion was also a significant factor in techniques using paste materials for registration to mount quadrant casts (Douglass, 1975). The discrepancy occurred when the cast was made of teeth "at rest", while the "bite registration" was made of teeth in maximum interdigitation. Invariably, an error will be introduced when the quadrant cast was placed in the registration paste for mounting purposes (Douglass, 1975).

\section{POLYETHER AS AN INTEROCCLUSAL RECORD}

Polyether was patented in 1969. Polyether was an elastomere. This elastomeric compound was made from polyethers terminated with amino groups crosslinked with such strong acids as aromatic sulfonic acid esthers. The crosslinked rubber was reported to have high dimensional accuracy after polymerization and storage (Wilson, 1977).

Docking (1970) stated polyether material possessed the highest recovery after deformation when compared to other elastomeres. It also had the least dimensional change following removal from the mouth.

The polyether system is a paste-paste system. Base paste contains an unsaturated polyether with imine end groups, a plasticizer, and a filler. The reactor paste contains an aromatic sulphonate, a 
plasticizer, and an inorganic filler. The setting reaction of a polyether is a cationic polymerization reaction. It involves crosslinking of imine groups (Combe, 1975).

Ramitec is a new interocclusal recording medium made of polyether. As yet, little is known about it. Research, however, is forthcoming. Chemical formula of Polyether:<smiles>CCC(OC(=O)COC(C)(C)OCC(=O)OC(CC)N(C)C)N(C)C</smiles> 


\section{SUMMARY OF 'THE REVIEW OF LITERATURE}

(Excluding Centric Occlusion - Centric Relation Controversy)

AUTHOR

Berman (1960)

Wirth and

Aplin (1971)

Berman (1960)

Shanahan and Leff (1960)

Millstein, Clark and Kronman (1973)
MATERIAL

\section{STATEMENT}

Ideal Interocclusal Bite Medium:

1) doesn't displace teeth

2) little dimensional change upon setting

3) remains rigid after setting

4) minimal resistance to closure

5) capacity and ease of verification

6) ease of use and modification

7) causes no adverse effects on tissues

dental waxes

Found softest wax required 102 grams for full penetration; hardest required 357 grams.

baseplate wax and impression wax base plate wax
Found neither wax permitted complete seating of casts; rendered only approximate accuracy.

Found:

1) Complete closure into the waxes was not achievable under pressures comparable to a clinical setting.

2) Storage in water produced the greatest change in dimension.

3) Considerable vertical and rotational changes occurred when cast placed into wax registration.

4) Exact reproduction of the original wax recordings was never achieved. 


\section{AUTHOR}

Tylman (1978)

Berman (1960)

Tylman (1978)

Wirth and Aplin (1971)
MATERIAL

waxes

ZOE

ZOE

ZOE

\section{STATEMENT}

Stated :

1) Waxes don't accurately reproduce the incisal and occlusal forms of teeth,

2) Wax spreads laterally in closure,

3) Considerable dimensional change caused by fluctuation in temperature,

4) Causes patient to close into undesirable patterns.

Stated:

1) Material mixed to a true fluidity,

2) Offered no resistance to closure,

3) Adhered to its carrier,

4) Set to a hard, noncompressible consistency,

5) Sharp and easily read,

6) Articulation of casts accomplished without distortion or compression of the record unequally in the vertical dimension

Stated: ZOE

1) Accurately reproduced incisal and occlusal forms of teeth,

2) Remains rigid with little or no dimensional change after setting,

3) Material can be easily reassembled if broken.

Mentioned difficulties with ZOE:

1) lengthy setting time,

2) tendency to fracture and stick to teeth,

3) details on record may surpass detail on casts. 
AUTHOR

Osborne (1969)

Strohaver (1972)

Douglass (1975)

DeMarco and

Paine (1974)

Goto (1971)

Docking (1970) Polyether

Wilson (1977)

Combe (1975)

\section{MATERIAL}

STATEMENT

Stated: Hand Articulation indicated when only small number of teeth must be replaced.

Stated: Least variable of a11 methods for mounting casts is hand articulation.

To control flexion of mandible, impression technique must register vertical dimension at or near the vertical dimension of occlusion.

Found distortion of mandible negligible up to $28 \%$ of maximal opening.

Found shifting of teeth occurred when dentition assumed maximal interdigitation. Impressions were made with mandible in static position.

Actual centric occlusion of patient thus not attained.

Stated: Polyether possessed highest recovery after deformation when compared to other elastomeres.

Stated: Polyether had high dimensional accuracy after polymerization and storage.

Described setting reaction of polyether: A cationic polymerization involving crosslinking of imine groups. 
CHAPTER III

METHODS AND MATERIALS

Thirty-one patients for this study were selected from amongst the dental school population of Loyola University. The following criteria were used for selection: 1) little restorative treatment, 2) presence of all teeth (with the exception of third molars or first bicuspids), and 3) adequate posterior and anterior occlusal stops.

Maxillary and mandibular alginate impressions were taken of each patient. These were poured in stone and mounted on a Whip-Mix articulator utilizing the face bow. The mandibular cast was mounted to the maxillary in centric occlusion using the hand articulation technique.

Interocclusal records were taken of each patient with four kinds of media: 1) two thicknesses of pink baseplate wax*, 2) reinforced wax, $* * 3)$ zinc oxide and eugenol paste $* * *$ and a COE frame carrier (Figure 1 and 4), a new polyether**** interocclusal recording medium. The material was utilized with and without a carrier.

The baseplate wax was cut in half and placed in a plastic bowl filled with very warm water for two minutes. It was then removed,

*Hygienic Company

**Lactona Company, Philadelphia.

***Kerr Bite Registration Paste, Sybron/Kerr, Romulus, Michigan. ****Premier Dental Products Company, Norristown, PA. 
folded to two thicknesses, and placed into the patient's mouth. It was removed and trimmed anterior-posteriorly so the anterior teeth would not be included in the record. It was also trimmed laterally to prevent the wax from impinging upon the inner surfaces of the cheeks. The wax was placed back onto the patient's mandibular posterior teeth bilaterally. The patient was instructed to close into centric occlusion. Cool water was directed on the wax for one minute with the teeth still occluding. The wax was carefully removed, air dried, wrapped in paper toweling, and stored in a cool place.

The reinforced wax (Figure 2) was placed in a warm water bath for one minute. It was placed onto the patient's mandibular teeth to determine if the wax needed trimming in the retromolar pad area. It was then removed and placed in the warm water bath for two minutes. The wax was placed back onto the patient's mandibular teeth. The patient was instructed to close into centric occlusion. Cool water was directed on the wax for one minute with the teeth still occluding. The wax was carefully removed, air dried, wrapped in paper toweling, and stored in a cool place.

A Coe frame (See Figure 3) was placed into the patient's mouth and adjusted for the proper width. If the frame was too long anteroposteriorly, the frame was trimmed. The investigator placed the Coe frame into the patient's mouth to avoid impingement of the plastic rim upon the teeth or soft tissues. The patient was asked to close into centric occlusion. He was asked if he was biting on 
the plastic part of the frame. If the plastic rim was impinging upon the teeth or soft tissues, the patient's response was immediate.

Zinc oxide and eugenol paste (See Figure 1) was then thinly placed on both sides of the frame. The carrier was then placed onto the patient's mandibular teeth. The patient was asked to close into centric occlusion. The paste was allowed to set for three minutes. The record was removed from the mouth, air dried, wrapped in paper toweling, and placed in a cool place.

The patient's teeth were then debrided of any remaining $\mathrm{ZOE}$ paste. Next, the polyether record (See Figure 4) utilizing a Coe frame was taken. Again, the frame was adjusted and placed in the mouth several times to give the investigator and patient a chance to practice taking the record.

The polyether accelerator and catalyst were placed in two oneinch lengths upon a mixing pad. The material was mixed to a uniform consistency and thinly placed upon both sides of the frame. This carrier was then placed onto the mandibular teeth. The patient was asked to close into centric occlusion. The polyether was allowed to set for five minutes, the manufacturer's suggested setting time. The interocclusal record was removed, air dried, wrapped in paper toweling, and placed in a cool place.

Next, the polyether was loaded into a syringe provided by the manufacturer (See Figure 4). It was simply injected onto the occlusals of the mandibular bicuspids and molars. The patient was 
asked to close. The material was allowed to set for five minutes. It was removed, air dried, wrapped in paper toweling, and stored with the other records.

RECORDING THE POSITION OF THE MAXILLARY CAST UTILIZING EACH OF THE INTEROCCLUSAL RECORDS

Centric occlusion was used to mount the casts to minimize the variables involved in this clinical study and to avoid the centric relation controversy. The hand articulated casts mounted in centric occlusion were used as the standard by which the interocclusal records were measured. Proper selection of patients and Strohaver's study on articulatormountings made the researcher confident that hand articulation was a proper standard. Hand articulation is reproducible. Reproducibility is an absolute necessity for a standard in this study.

The ZOE paste registration and the two polyether interocclusal records were carefully trimmed with a Bard Parker blade. Excess bulk around the buccal, lingual, and interproximal areas of the intaglios of the teeth were trimmed away to prevent improper seating of the maxillary cast to the mandibular.

The condyle heads were removed from the Whip Mix articulator and a Buhnergraph was screwed on in place of them (See Figure 5). Graph paper attached to cardboard was placed on the condylar housing using double stick tape. The cardboard reinforced the graph paper to prevent distortion while making the recordings. The double stick 
tape kept the graph paper firmly attached to the housing. Stamp pad inks of different colors were used to make the recordings (See Figure 6).

First, the position of the maxillary cast when hand articulated with the mandibular cast was determined. The casts were placed in centric occlusion. Black ink was placed on the Buhnergraph styli. With the casts carefully supported, the positions of the tips of the pointer rods were marked on the graph paper. The ink was cleaned off the styli and a different color ink was placed on them. An interocclusal record was placed on the mandibular cast. The maxillary cast was set into it. The casts were carefully supported in the imprints of the record. Again the positions of the tips of the styli rods were marked on the graph paper. This procedure was repeated for each interocclusal record (See Figure 7).

The distance between the position of the hand articulated casts and the casts mounted into the interocclusal record was then measured. The measurements were made on a Gaertner traveling microscope micrometer. 
Figure 1
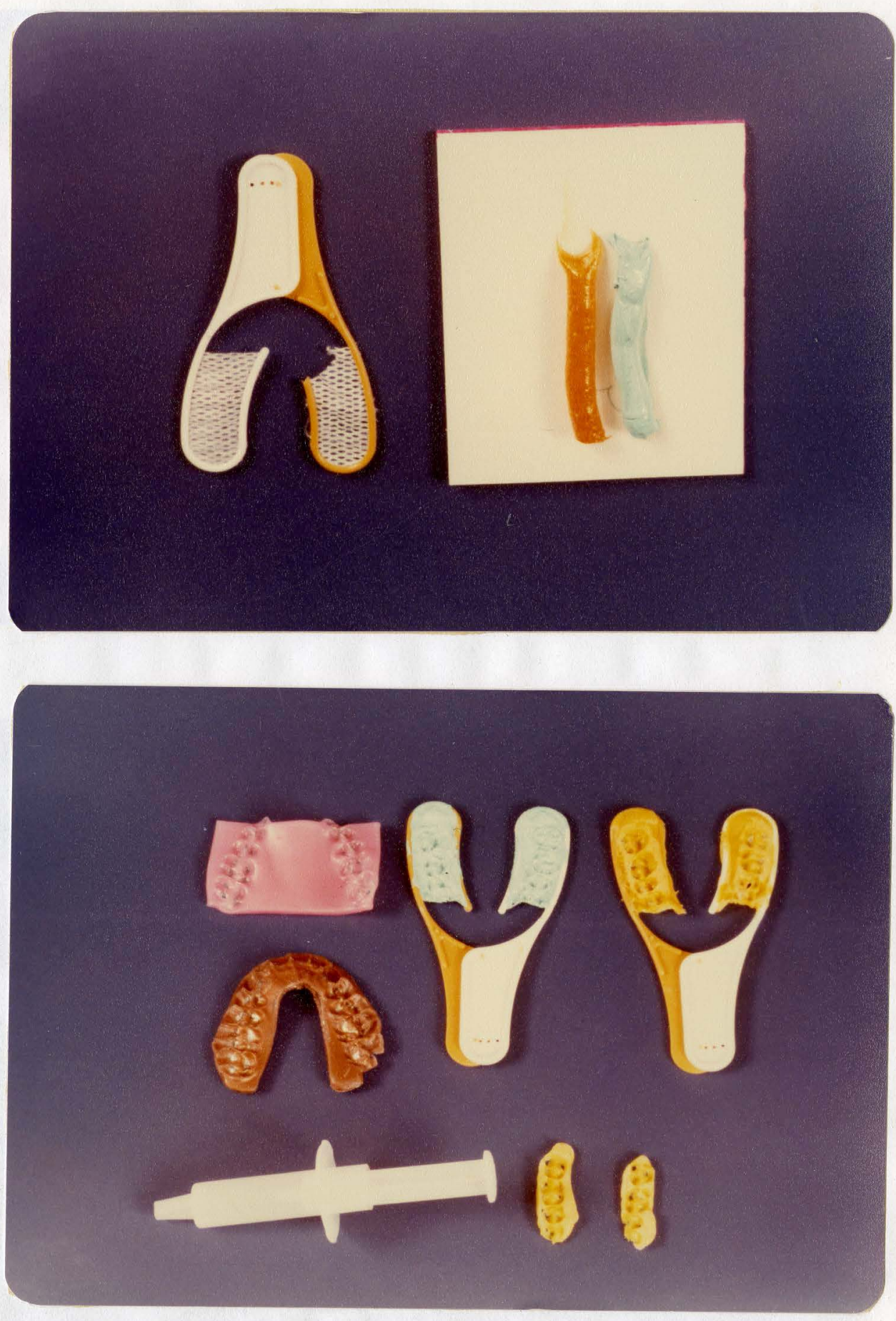
Figure 2
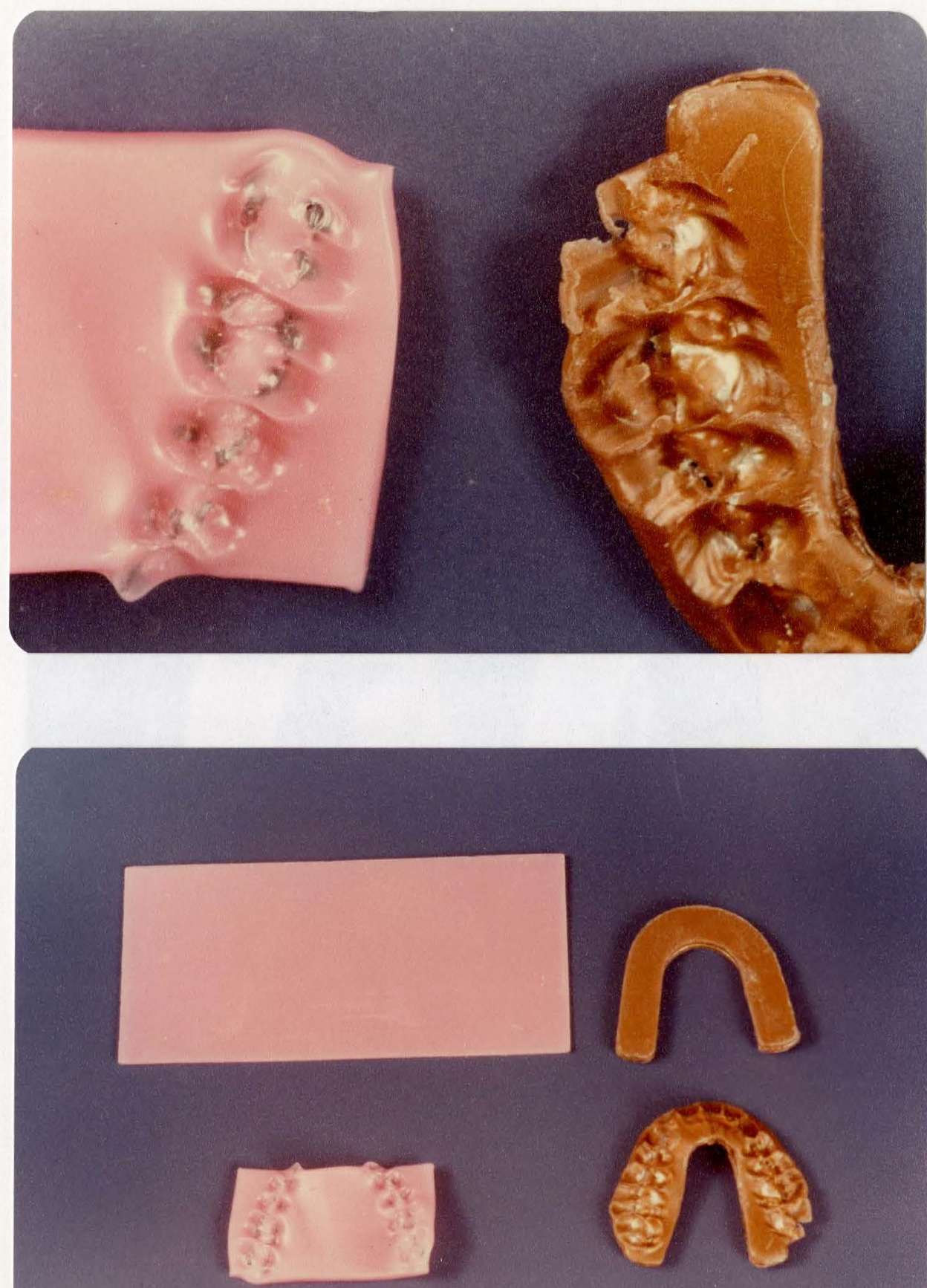
Figure 3

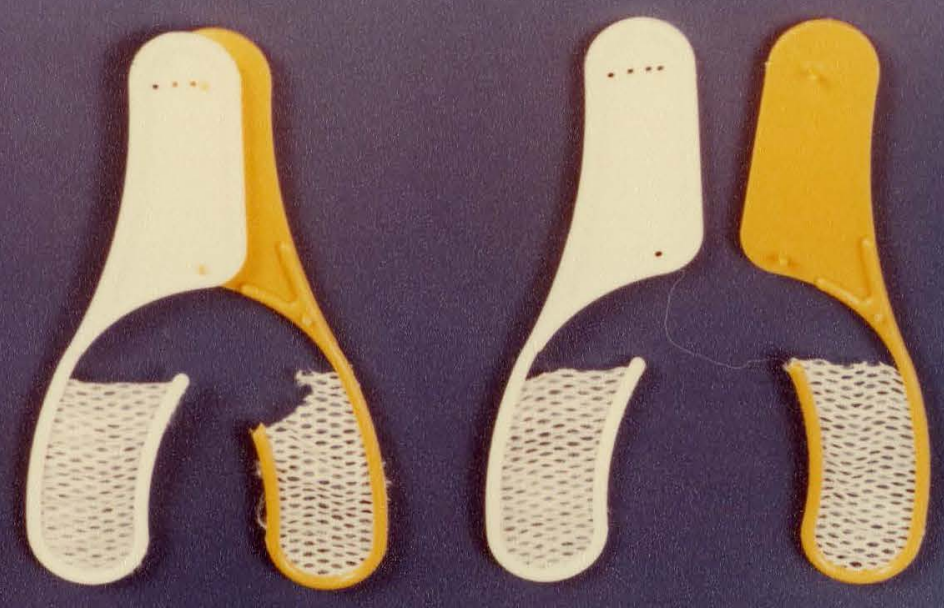


Figure 4
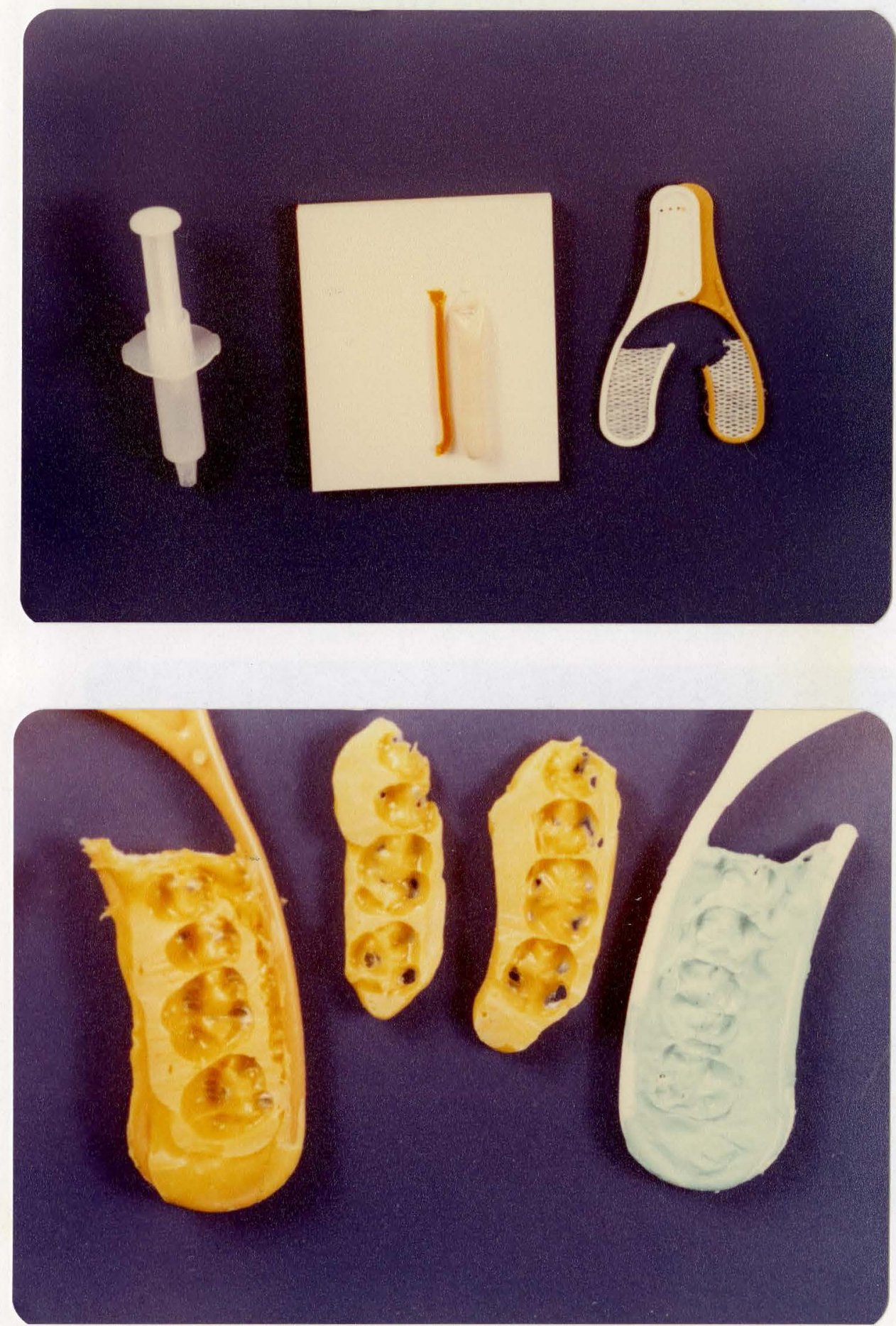
Figure 5

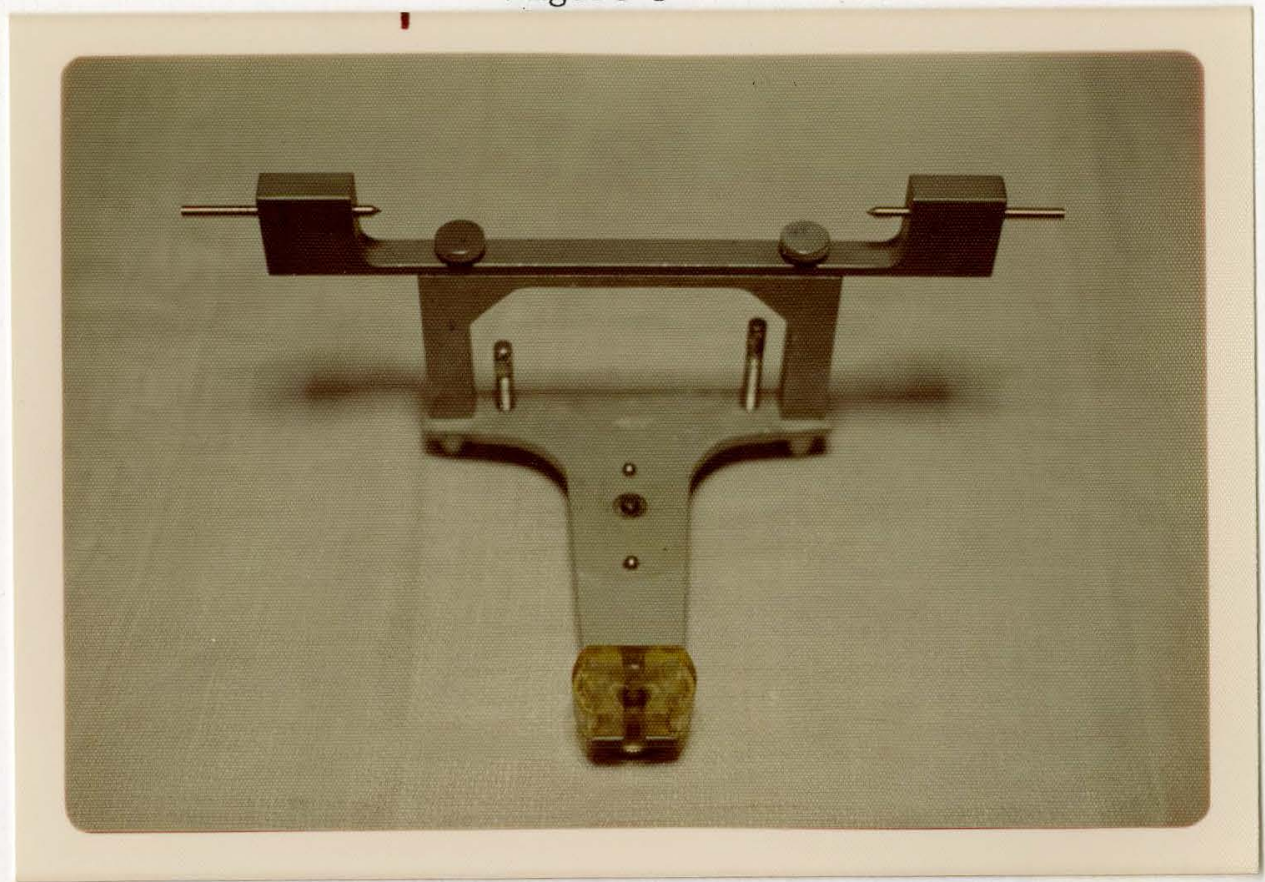

Figure 6

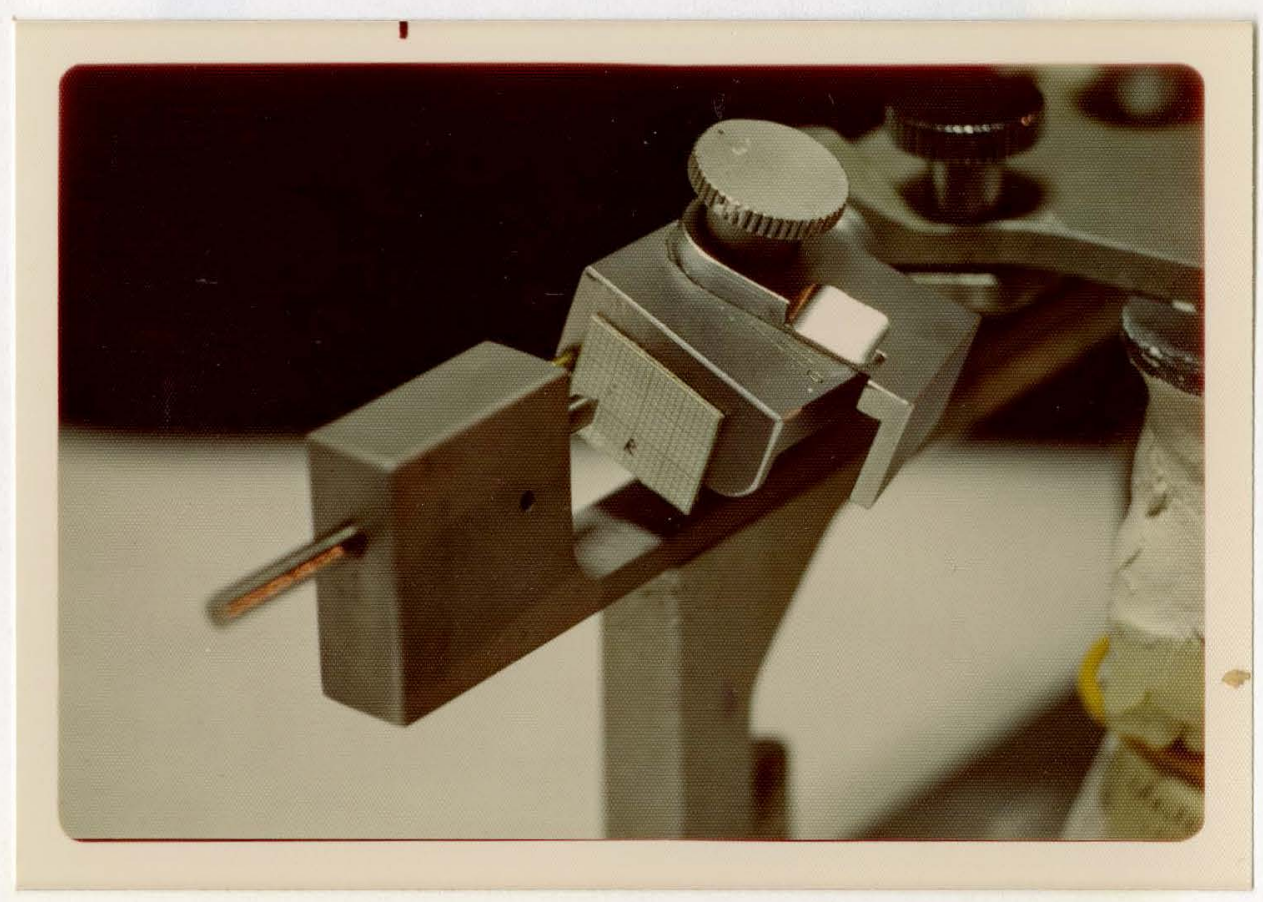


Figure 7

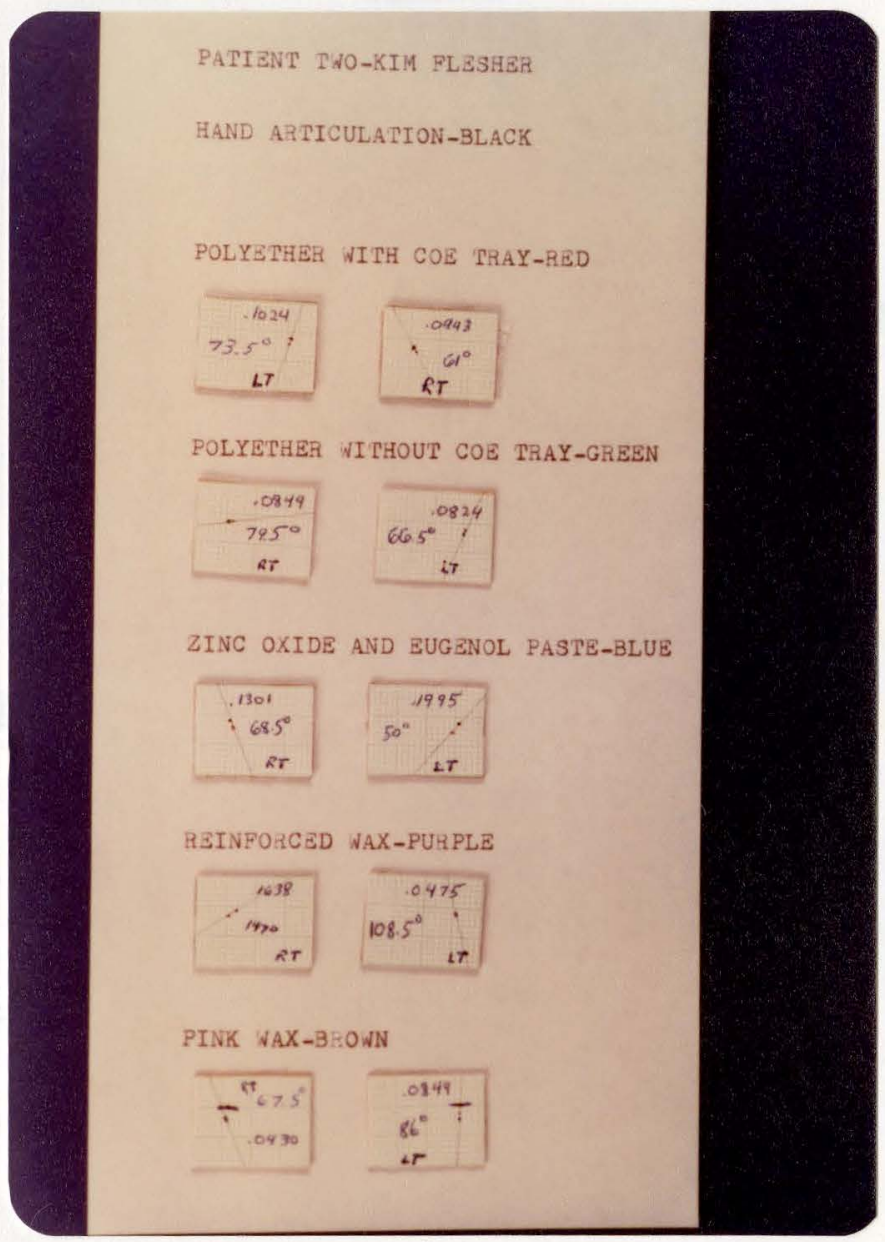


CHAPTER IV

EXPERIMENTAL RESULTS

Table 1

Means and Standard Deviations of Four

Interocclusal Records

$\underline{\text { Means }}$

$\underline{\text { Standard Deviations }}$

Pink Wax

$\mathrm{X}$-Vector

.0102

.0760

Y-Vector

.2180

.0797

Rotation

.0375

.5037

Declanation

$-.0870$

.6718

Reinforced Wax

$\mathrm{X}$-Vector

$-.0203$

.0581

Y-Vector

.1650

.0755

Rotation

$-.0298$

.3950

Declanation

.0830

.3254

Polyether With Coe Tray

$\mathrm{X}$-Vector

$-.0099$

.0953

.0154

.0333

Y-Vector

Rotation

$-.0500$

.0586

.1813

Declanation

.2392

Polyether Without Coe Tray

$\begin{array}{lrr}\text { X-Vector } & -.0066 & .0171 \\ \text { Y-Vector } & .0325 & .0218 \\ \text { Rotation } & -.0230 & .1152 \\ \text { Declanation } & -.0069 & .0954\end{array}$


Means

Standard Deviations

$\underline{Z O E}$

$\mathrm{X}$-Vector

$\mathrm{Y}$-Vector

$-.0116$

.0290

Rotation

.1067

.0542

Declanation

.0178

.2325

.0174

.2327

The right and left poles of the articulator hinge axis have been condensed to four factors of displacement:

1) $\mathrm{X}$-Vector - $\mathrm{X}$ is the displacement anterior-posteriorly of the center of the hinge axis

2) Y-Vector - $\mathrm{Y}$ is the displacement vertically of the center point of the hinge axis

3) Rotation - the degree of angular displacement in the horizontal plane

4) Declanation - the angular displacement in the sagittal plane as measured from the center of the hinge axis

The plane of the graph paper attached to the condylar housing is tangent to the arc defined by the articulator hinge axis. A vector originated from a point representing the original centric occlusion position (CO). The vector terminated at a point representing the new $C O$ position. The investigator thus measured a vector in space and a projection in the given plane (horizontal or vertical).

The mandibular cast was the moving member not the maxillary cast. The upper cast is fixed due to facebow utilization. The graph paper is also part of the fixed upper cast. The maxillary cast is fixed. The lower cast is mounted to it. It is important to understand this concept. The maxillary cast cannot be thought of as 
a floating member. To do so is to misinterpret how the standard was obtained. In the clinical lab procedures, the standard was always obtained by mounting the mandibular cast to the fixed maxillary. When interocclusal records are placed between the casts, the investigator is again mounting the lower cast to the upper. The Buhnergraph, mandibular cast, and lower component of the Whip Mix articulator were in effect moving about the fixed maxillary cast as determined by the facebow.

THE MOVEMENTS MADE BY THE MANDIBULAR CAST WERE REFERENCED TO THE CENTER OF THE HINGE AXIS OF THE ARTICULATOR.

ANY WAY THE MANDIBULAR CAST MOVED, THE CENTER OF THE ARTICULATOR HINGE AXIS ALSO MOVED.

THE MOVEMENTS MADE BY THE MANDIBULAR CASTS ARE VERTICAL, HORIZONTAL, AND LATERAL. LATERAL MOVEMENT, AS MENTIONED, COULD NOT BE MEASURED.

From the data the investigator analyzed: 1) Bodily movement of the center of the articulator hinge axis in space; 2) Angular displacement of the hinge axis around its center in two planes - in the horizontal plane (or rotation) and in the vertical plane (or declanation).

In this study the investigator measured the $\mathrm{X}$ and $\mathrm{Y}$ displacement of the two poles (left and right) of the hinge axis and rotation and declanation of the hinge axis around its center. These measurements were used for the statistical analysis.

An interocclusal record when placed between the teeth can cause both vertical and horizontal movement - not a pure movement. It is 
necessary to divide this movement into its component parts $-\mathrm{X}$ and $\mathrm{Y}$. The distance from the centric occlusion position (CO) to the new position as determined by the interocclusal record ( $\mathrm{CO}^{\prime}$ ) was known. The angle $\theta$ formed by the line $\mathrm{CO}-\mathrm{CO}^{\prime}$ with the horizontal line determined by the Frankfurt Horizontal plane was determined through use of a protractor. Because the condylar housings were set at $30^{\circ}, 30^{\circ}$ had to be added to the angle formed by the $\mathrm{CO}-\mathrm{CO}^{\prime}$ line and the horizontal base line in order to establish the angle $\theta$. (See Figure D).

Through use of trigonometry, the X-component was determined to be: $\overrightarrow{\mathrm{X}}=\cos \theta$ (Hypotenuse) $\overrightarrow{\mathrm{Y}}=\operatorname{SIN} \theta$ (Hypotenuse) (See Figure E)

Rotation was the next factor of displacement considered. To determine rotation, geometric assumptions were made:

1) WHEN THE MANDIBULAR CAST CHANGED POSITIONS, THE POINTERS MARKED THE INTERSECTION OF THE GRAPH PAPER WITH THE MANDIBULAR AXIS

2) GIVEN A LINE (LINE A), AND ANOTHER LINE (LINE B), NOT PARALLEL TO LINE A, AND AN INTERSECT ANGLE $\theta$

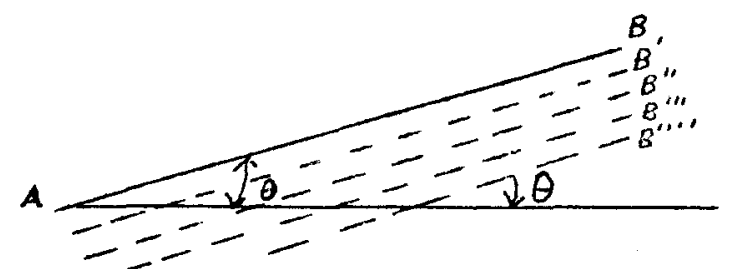

ALI LINES PARALLEL TO LINE B HAVE SAME INTERSECT ANGLE.

3) CONSTRUCT A LINE PARALLEL TO BUHNERGRAPH STYLI THAT INTERSECTS ONE OF THE GRAPH PAPERS AT THE POINT OF THE MAXILLARY HINGE AXIS. CALL LINE $M^{\prime}$. (See Figure F).

The maxillary cast axis is equal to the diameter of the Whip Mix upper member from the outer surface of the right condylar housing to 


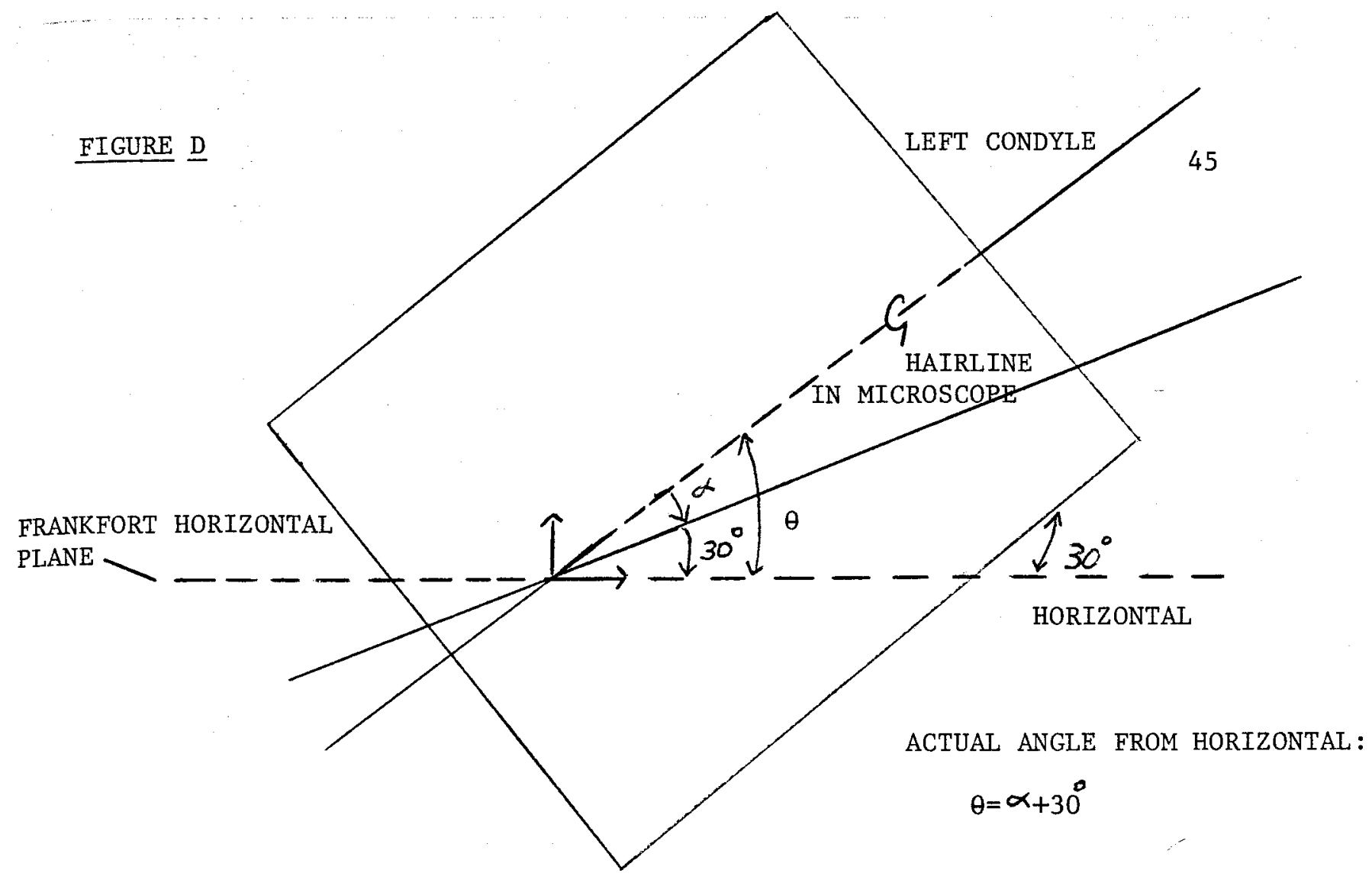

FIGURE E

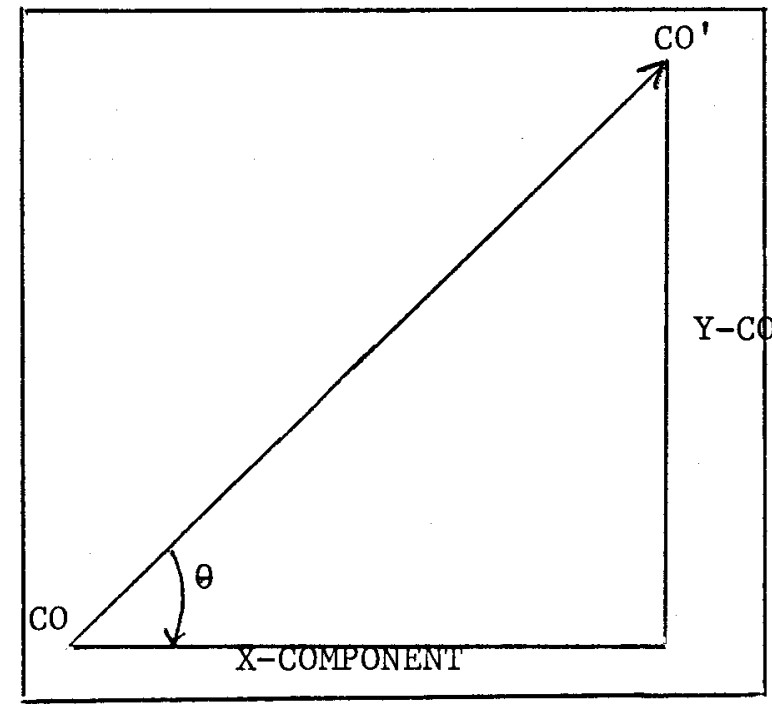

ENLARGEMENT OF CONDYLAR POINTS ON GRAPH PAPER
CO=ORIGINAL CENTRIC OCCLUSION POSITION

$\mathrm{CO}^{\prime}=$ NEW CENTRIC OCCLUSION POSITION AS DETERMINED BY THE INTEROCCLUSAL RECORD

\section{$\overrightarrow{\mathrm{XY}}$ DISPLACEMENT (DISTANCE, DIRECTION)}

$X$ COMPONENT $=\operatorname{COS} \theta$ (HYPOTENUSE)

$\theta=$ ANGLE MEASURED WITH PROTRACTOR HYPOTENUSE=DISTANCE MEASURED FROM CO ESTABLISHED BY HAND ARTICULATION TO $C^{\prime}$ ESTABLISHED BY INTEROCCLUSAL RECORD

$\overrightarrow{\mathrm{Y}}=\mathrm{SIN} \theta$ (HYPOTENUSE) 


\section{FIGURE F}

M = MANDIBULAR AXIS AFTER BITE REGISTRATION

$M^{\prime}=$ LINE CONSTRUCTED PARALLEL TO M

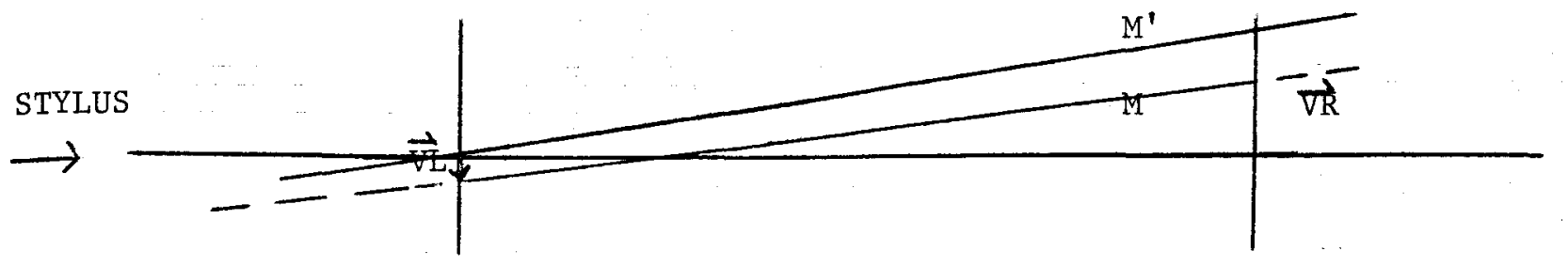

GRAPH PAPER

STYLI POINT TO LINE REPRESENTING MAXILLARY AXIS

MAXILLARY AXIS=MANDIBULAR AXIS AT CO ESTABLISHED BY HAND ARTICULATION

$$
\mathrm{VT}=\overrightarrow{\mathrm{VR}}-\overrightarrow{\mathrm{V}}
$$

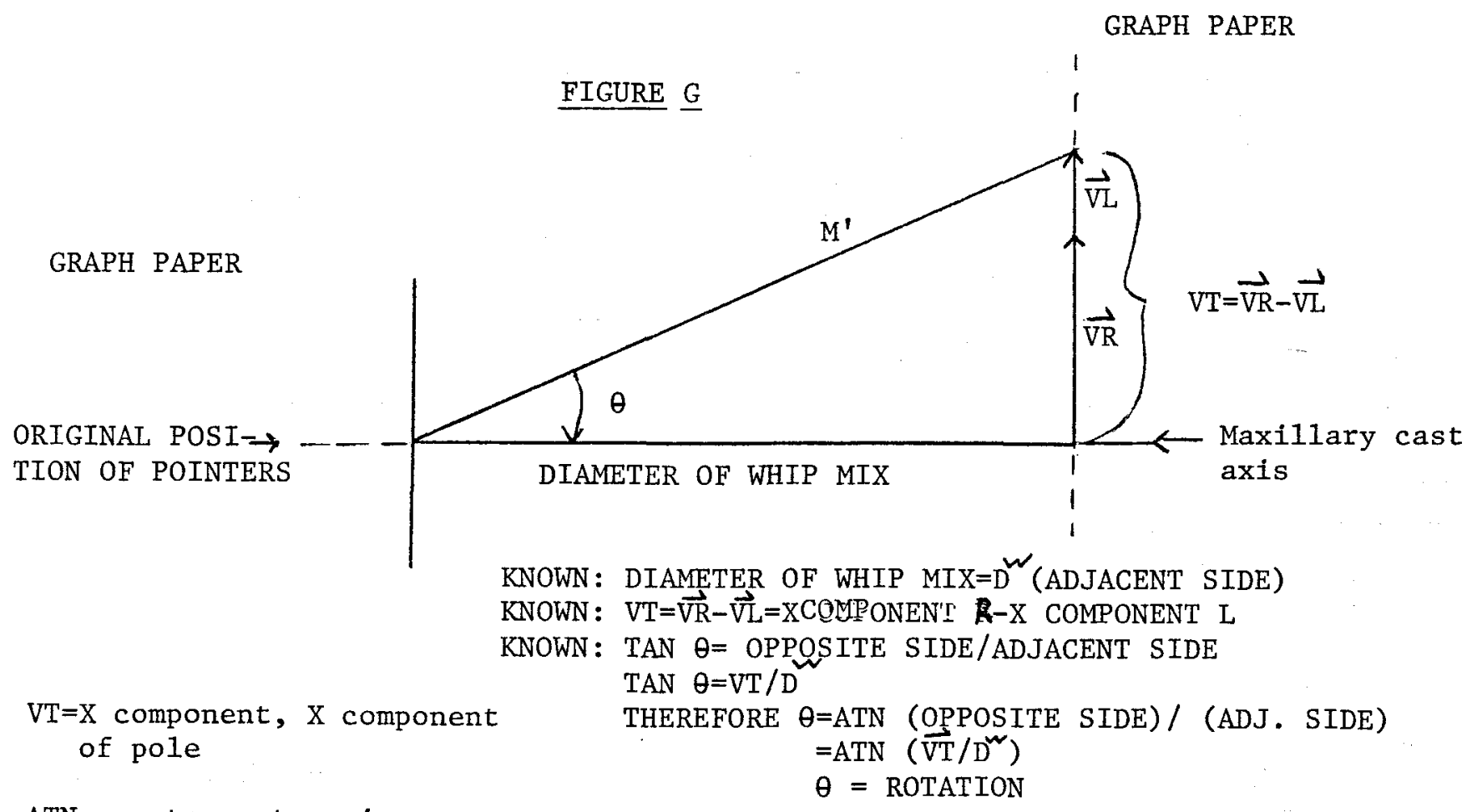

$\mathrm{ATN}=\operatorname{arc}$ tangent or inverse tangent 
the outer surface of the left condylar housing plus 2mm. Each graph paper was $1 \mathrm{~mm}$ in thickness due to the cardboard mounts. Two $\mathrm{mm}$ was thus added to the diameter of the Whip Mix. $\overrightarrow{V T}$ is equal to $\overrightarrow{V R}-\overrightarrow{V L}$. $\overrightarrow{V R}$ is known. $\overrightarrow{V R}=\mathrm{x}$ component right. This was previously measured. $\overrightarrow{V L}=X$ component left. This was measured. Thus rotation $=\operatorname{TAN}^{-1}(\vec{H} / R)$ or $1 /$ TAN $(\vec{H} / R)$. (See Figure $G)$.

Declanation was determined the same was as rotation except $\mathrm{VT}=\overrightarrow{\mathrm{VR}}-\overrightarrow{\mathrm{VL}}$ where $\overrightarrow{\mathrm{VR}}=\mathrm{Y}$ component right. $\overrightarrow{\mathrm{VL}}=\mathrm{Y}$ component left. Declanation $=\operatorname{TAN}^{-1}(\vec{V} / R)$ or $1 /$ TAN $(\vec{V} / R)$.

Thus the angular displacement in a given plane (Horizontal $=$ ROTATION, Vertical $=$ DECLANATION) is therefore the inverse tangent of the rotation displacement vector divided by the diameter of the instrument.

Rotation and declanation have been established. However, $\vec{X}$ and $\vec{Y}$ are displacement components determined for both the left and right sides. Data cannot be effectively analyzed unless the $\mathrm{X}$ and $\mathrm{Y}$ poles are condensed in terms of the movement of the center of the articulator hinge axis.

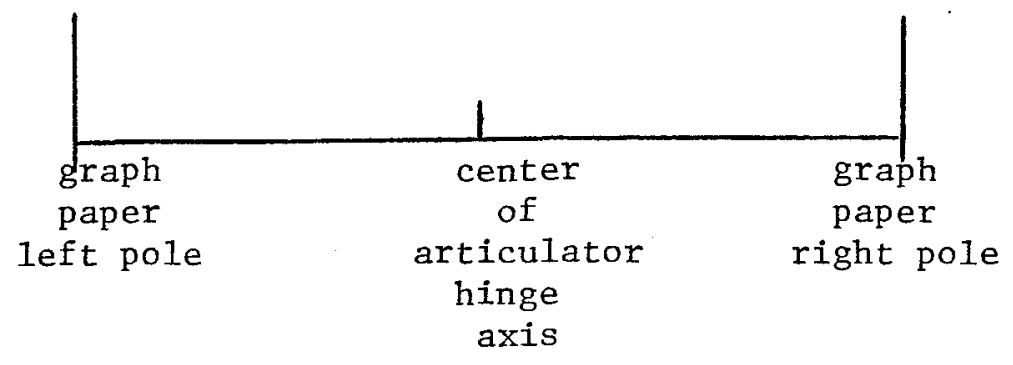

(See Figure $\mathrm{H}$ ). 
F IGURE H

$\overrightarrow{S V}=$ CONDENSATION OF 2

LINE THROUGH CENTER OF ARTICULATCR HINGE AXIS

POLES IN $X$ PLANE

ROT $V_{L}$
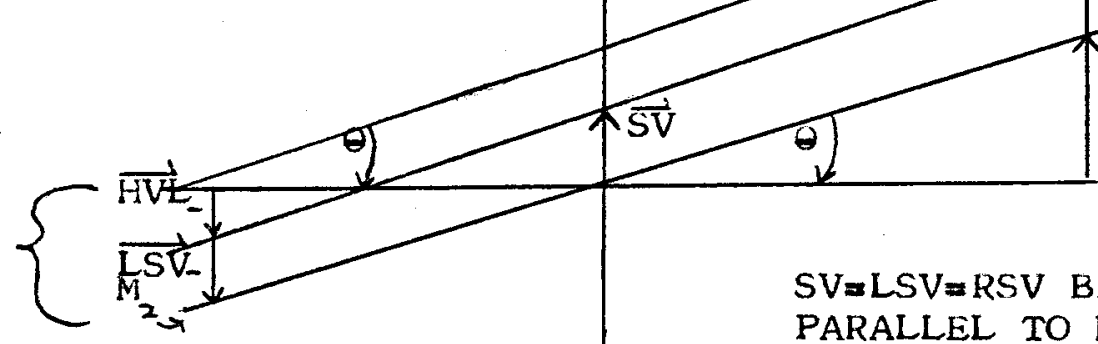

$\overrightarrow{\mathrm{HVR}}$ ROT $V_{R}$ 
$\overrightarrow{\mathrm{HVL}}=\mathrm{X}$ component left. This is known.

$\overrightarrow{\mathrm{HVR}}=\mathrm{X}$ component right. This is known.

$\overrightarrow{\mathrm{SV}}=$ the movement of the center of the articulator hinge axis as determined by the $\mathrm{X}$ components of both the left and right sides.

Baseline=maxillary cast

$\mathrm{M}_{0}=$ line formed by mandibular member when interocclusal record is placed between casts.

$\mathrm{M}_{1}$ and $\mathrm{M}_{2}$ are lines drawn parallel to $\mathrm{M}_{0}$.

Because $\mathrm{M}_{0}$ and $M_{2}$ are parallel, $\mathrm{SV}=\mathrm{LSV}=\mathrm{RSV}$

$|S V|=|1 / 2(\overrightarrow{\mathrm{HVR}}+\overrightarrow{\mathrm{HVL}})|$ or the movement of the center of the articulator hinge axis is equal to $1 / 2$ the movement of the right and left $X$ components.

For the determination of the movement of the center of the articulator hinge axis in terms of the right and left $Y$ components, the same geometrical explanation as Figure D was used. However, the right and left $\mathrm{Y}$ components were substituted for $\overrightarrow{\mathrm{HVt}}$ and $\overrightarrow{\mathrm{HVR}}$. Thus $\mathrm{Y}=$ $\overrightarrow{(\mathrm{LV}}+\overrightarrow{\mathrm{RV}}) / 2$ where $\overrightarrow{\mathrm{LV}}=1$ eft vertical component and $\overrightarrow{\mathrm{RV}}=$ right vertical component.

A statistical analysis (F RATIO) was used to analyze the data for the four components of movement for each of the materials studied. (See Table 2).

For the comparison of all 5 treatments, the $F$ ratio of 38.525 for the Y-vector was statistically significant. The waxes, with their great resistance to closure, were the probable cause of this vertical displacement.

Rotation, declanation, and the anteroposterior components of 
Table 2

F RATIOS

Statistical Significance *

$$
\underline{\overrightarrow{\mathrm{X}}} \quad \underline{\dot{\mathrm{Y}}} \quad \text { ROTATION } \quad \text { DECLANATION }
$$

Reject Nul1 Hypothesis if F>2.44 at .05 1evel.

Five Treatments

Compared

$2.065 \quad 38.525 * \quad .261$

1.118

Reject Null Hypothesis if F>4.17 at .05 level.

$\begin{array}{lcccc}\text { Zoe and Polyether } & .068 & .719 & 2 \times 10^{-3} & 1.389 \\ \text { With Coe Tray } & & & & \\ \text { Pink Wax and Poly- } & 1.648 & 1.648 & .409 & .425\end{array}$

ether Without Coe

Tray

Pink Wax and Rein-

3.83

$6.876 *$

.328

1.878

forced Wax

Reinforced Wax and

1.396

$87.234 \%$

.01

2.124

Polyether Without

Coe Tray

Polyether With Coe

.367

$34.437 \%$

.744

Tray and Polyether

Without Coe Tray

Reinforced Wax and

.728

$17.452 *$

.306

3.757

Polyether With Coe

Tray

Zoe and Polyether

.837

$45.968 *$

1.102

Without Coe Tray

Reject Nul1 Hypothesis if Fr3.15 at .05 level.

Reinforced Wax,

2.552

$65.423 *$

.299

1. 264

Pink Wax, and Poly-

ether Without Coe

Tray

ZOE, Polyether With

$23.09 *$

and Without Coe Tray 
movement were all insignificant. Centric occlusion was probably responsible for these results. With centric occlusion a patient has definite stops which his neuromuscular mechanisms are "programmed" to locate. Patients can find their intercuspal position. They may not be able to close into it completely due to an intervening material, but they "know" where the position is located. With centric relation we have a different situation. Declanation and the $\mathrm{X}$-vector could be significantly affected when the mandible is "de-programmed."

The next analysis of variance comparison was $\mathrm{ZOE}$ and polyether with a Coe Tray. Both materials utilized a carrier. The investigator was interested in finding out how the materials compared to each other (Coe Tray carrier variable cancelled out).

The results for all 4 components of displacement were as expected. The F ratios for all 4 components of displacement were insignificant. ZOE and polyether have, little if any resistance to closure. The materials are fluid-like. Closure into centric occlusion is unimpeded.

The next analysis of variance run was pink wax and polyether without a Coe Tray. Al1 $4 \mathrm{~F}$ ratios were insignificant. The results were not as expected. Polyether is a material with little resistance. Pink wax has a great deal of resistance to closure.

Pink wax and reinforced wax were compared. The two waxes were significantly different in the vertical plane. Anteroposterior deviation, although statistically insignificant, was more pronounced than with other materials. 
Reinforced wax and polyether without a Coe Tray were next examined. The two materials were significantly different in the vertical displacement analysis. This was as expected. Reinforced wax has a great deal of resistance to closure.

Polyether with Coe Tray and polyether without Coe Tray were compared. For this analysis all results were as expected. However, the Y-vector $F$ ratio was a little surprising ( $F=34.437)$. Rotation, declanation, and anteroposterior displacement were expected to be negligible. Polyether has no resistance to closure. To be so statistically significant in the vertical plane was due to the carrier.

Reinforced wax and polyether with Coe Tray were next examined. The results indicated reinforced wax caused a significant amount of displacement of the center of the articulator hinge axis in the vertical plane. This again was caused by its resistance to closure.

Declanation was insignificant, but the $\mathrm{F}$ ratio of 3.757 indicated reinforced wax was capable of causing a deviation in the sagittal plane.

ZOE and polyether without a Coe Tray were compared. The F ratio was statistically significant in the $Y$ plane. Interference from the tray can be assumed to be the responsible factor since ZOE and polyether have no resistance to closure.

Reinforced wax, pink wax, and polyether without Coe Tray were compared. The results indicated waxes have resistance to closure in the vertical plane. The anteroposterior displacement was insignificant but an $F$ ratio of 2.552 indicated waxes can cause anteroposterior 
deviation of the center of the articulator hinge axis.

ZOE, polyether with and without a Coe Tray were compared only in the vertical dimension ( $Y$-vector). The $F$ ratio was 23.09 for this analysis. The Coe Tray carrier was probably responsible for the statistically significant $F$ ratio for the $Y$-vector. 


\section{CHAPTER V}

\section{DISCUSSION}

This study is attempting to examine and measure a three-dimensional displacement of the center of the Whip Mix articulator hinge axis in two dimensions. This is a geometrical projection in 2-D of a 3-D clinical situation (def. Projection $=N-1$ representation of an N dimensional object).

The Buhnergraph can measure only anteroposterior and vertical components of displacement of the articulator hinge axis. It cannot measure pure lateral components of movements. That is, a sideshift invoked by the material cannot be detected by this recording device.

For this study, the lateral component of movement does not negatively affect the validity of the Buhnergraph recordings. In fact, this shortcoming of the device favors the interocclusal records used in this study. The resistance of waxes are notorious for causing displacement of the maxillomandibular relationship. However, if a wax displaces the mandible latera11y, this malposition will not be recorded. The material will in fact appear to be more clinically useful than it actually is (Figure A).

\section{ASSUMPTIONS MADE IN THIS STUDY:}

1. The investigator is studying a representation of a patient's hinge axis as determined by the Whip Mix face-bow. 
2. In the experimental design of this study, the investigator is assuming the hinge axis is related to the mandibular member of the articulator in a proper centric occlusion without an intervening material (Hand Articulation = Standard).

3. Interocclusal recording media have the potential to cause errors in both clinical patient procedures and cast mounting procedures. No matter what the mechanism behind the alteration of the center of the hinge axis of the articulator, the sum total of these errors will manifest themselves as two dimensional displacements of the poles of the articulator hinge axis.

4. The Null Hypothesis states: Interocclusal recording media do not alter the position of the center of the articulator hinge axis in space.

In analyzing the data obtained in this study, the anteroposterior component of movement, $\mathrm{X}$, and the vertical component, $\mathrm{Y}$, must be considered separately. Declanation and Rotation are a part of the X and $Y$ movement. A pure vertical and pure anteroposterior movement probably rarely exists when an interocclusal media is placed between the teeth. Declanation is the angular displacement in the sagitta1 plane as measured from the center of the hinge axis. Rotation is the degree of angular displacement in the horizontal plane. FIGURE A

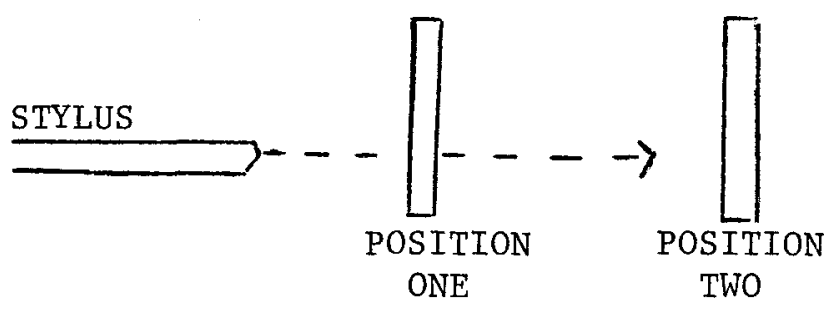


FIGURE B

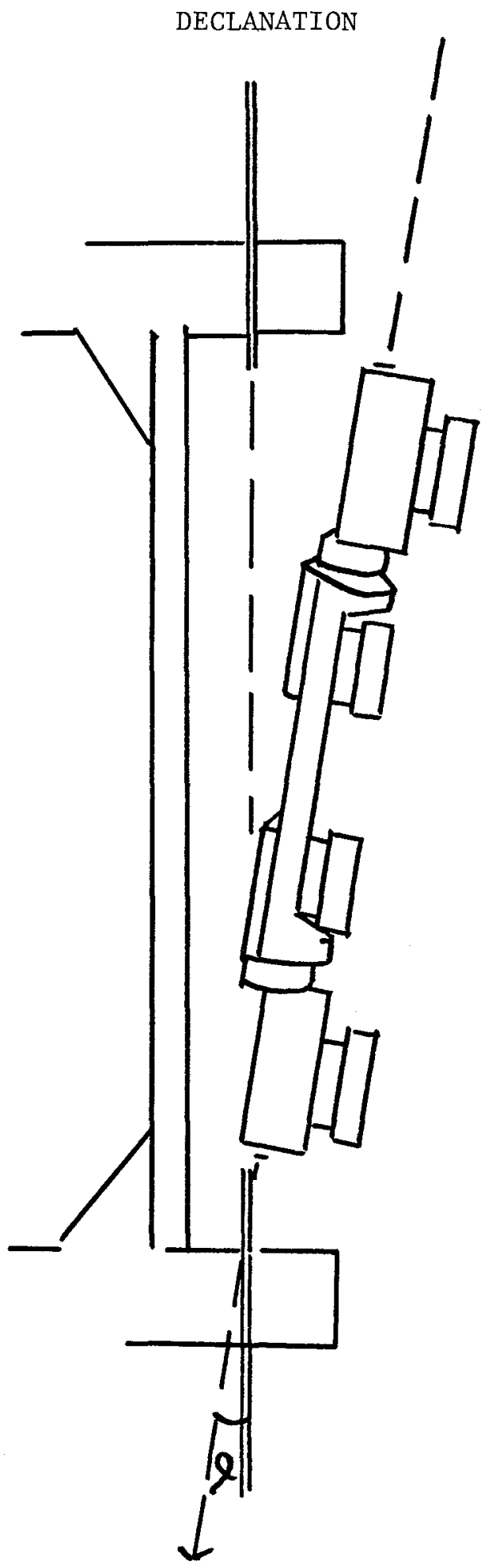


FIGURE C

ROTATION - As Seen From Above

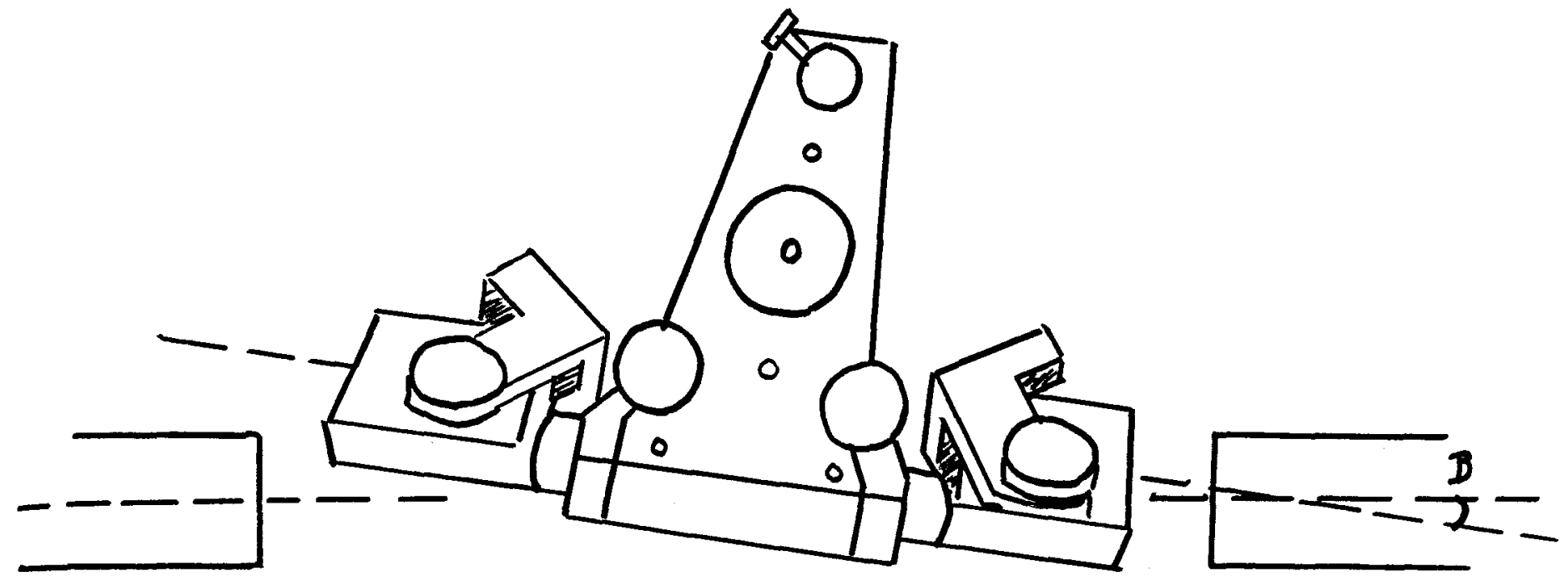




\section{LIMITATIONS OF STUDY:}

\section{EXPERIMENTAL DESIGN}

1. Reiterating a point previously discussed, this study is based on a two-dimensional projection of a three-dimensional entity in space.

2. The lateral component of movement, although not negatively affecting the study, cannot be measured with a Buhnergraph. Poor interocclusal recording media can appear to have more clinical usefulness than actually exists.

The investigator attempted to control the following variables. However, the clinical judgment required is a variable itself.

\section{CLINICAL TECHNIQUE}

3. Improper impression technique can minimize the usefulness as a standard of the hand articulated casts in centric occlusion. Taking alginate impressions at a significantly open vertical dimension will give a centric occlusion different from that which the patient can attain. The interocclusal records are taken with the teeth in maximum intercuspation. These records will not appear as satisfactory as they might be when compared to this standard. Flexion of the mandible is the cause of this problem.

4. If the patient does not completely close into the interocclusal recording material until his teeth come together in centric occlusion, the record reproduced will be incorrect. The true nature of the interocclusal material will not be recorded. Patients often 
do not know whether they have closed all the way through a material. MOUNTING PROCEDURES

5. The improper mounting of the mandibular cast to the maxillary cast in centric occlusion could invalidate the standard for that particular patient. If the investigator does not carefully note wear facets, anterior and posterior stops, the plane of occlusion of all teeth, malposed teeth, etc. an improper hand-articulated mounting in centric occlusion will result.

6. Failure to properly trim interocclusal records could result in improper seating of the maxillary cast into the recording media. Incorrect recordings will result.

\section{COLLECTION OF DATA}

7. Articulating the maxillary and mandibular casts and then marking the graph paper grid with the Buhnergraph styli is both arduous and critical. If the maxillary cast is not properly and carefully held into the record, the upper member of the articulator will declanate slightly. The wrong position will then be recorded.

8. The Gaertner Traveling Microscope Micrometer is another possible source of error in this study. If the micrometer is not calibrated at properly designated intervals, "play" in the vernier will result in inaccurate recordings. 
COMPARISON OF RESULTS TO LITERATURE AND ITS CLINICAL IMPLICATIONS:

Zinc oxide and eugenol was compared with polyether utilizing a Coe tray. The rotation analysis of variance was negligible. Declanation, anteroposterior, and vertical analysis of variance were insignificant. It can be concluded from this study the two materials utilizing a carrier behave equally well.

Berman (1960) and Tylman (1978) stated ZOE was the material of choice for an interocclusal record. They said the material mixes to a true fluidity and offers no resistance to closure. This study did not indicate $\mathrm{ZOE}$ was the material of choice for an interocclusal record. It did, however, bear out the claims Berman and Tylman made for the fluidity and lack of resistance to closure of $\mathrm{ZOE}$.

Reinforced wax and polyether without a Coe tray were compared. The $F$ ratio for the Y-vector was statistically significant. It can be concluded reinforced wax, due to its resistance to closure, dimensional instability, and deformation-prone nature is an unreliable interocclusal record.

Reinforced wax and polyether with a tray were compared. The F ratio for the vertical dispacement vector was statistically significant. Declanation came very close to significance. Again, it can be concluded the inherently poor nature of reinforced wax caused the deviations indicated.

Reinforced wax, Pink wax, and polyether without a tray were compared. Again the Y-vector had a statistically significant F ratio. 
Waxes are poor interocclusal records. This study confirms the work of Berman (1960), Shanahan and Leff (1960), and Millstein, Clark, and Kronman (1973). It supports the claims of Nagle (1959), Silverman (1957), and Tylman (1978).

\section{CLINICAL SIGNIFICANCE OF STUDY}

For the dental clinician interocclusal recording waxes are best left alone. Compared to other available recording media, they are decidedly inferior.

Zinc oxide and eugenol paste is a very good interocclusal recording material. Polyether with a carrier is equally good. However, there are some disadvantages with both of these materials.

ZOE cracks and sticks to the teeth. Vital parts of it can be lost through this breakage. Once the record has been used to mount casts, it can no longer be used again. Wirth and Aplin noted these disadvantages in 1971.

ZOE must be trimmed. The flash around the intaglios of the teeth, unless cut back, can prevent the accurate seating of casts. This is especially true of polyether.

There is a "spring" to this elastomere. There is also a decided amount of friction in seating a stone model into it. If polyether is not trimmed and carefully seated into casts, it can be worse than any material examined in this study.

As a matter of fact, if this investigator had not trimmed $\mathrm{ZOE}$ and Ramitec in the 3 treatments out of 5 presented in this study, 
there is a good possibility the Null Hypothesis could have been proved.

Polyether and ZOE must be used thinly. This is important for ZOE and critical for polyether. Too much polyether around the intaglios of the teeth will significantly prop open a pair of casts.

The chemical setting recording media studied are not especially easy to use, if any are. They are relatively convenient to use clinically but they prove to be more difficult to utilize in the clinical lab procedures. This is extremely important for the dental clinician to realize. Unfortunately, only the laboratory technician seems to understand this we11. He uses HAND ARTICULATION.

The results of this study indicated polyether without a coe tray was the best interocclusal recording material studied. The carrier appeared to interfere with proper centric jaw closure. The investigator was careful to keep the plastic frame part of the carrier away from the occluding surfaces of the teeth. However, the frame often touched the inner surfaces of the cheeks and other soft tissues. This might have set up a negative neuromuscular response in the patient resulting in a less than optimum centric occlusion.

\section{FUTURE STUDTES}

To improve future studies using a Buhnergraph, a third point should be devised to record lateral displacement. A hinged needle attached to the Buhnergraph might be a solution. Interocclusal materials with and without resistance could then be more accurately 
compared to each other. Their clinical usefulness could be more comprehensively evaluated.

Clinical research involves many variables---some that can and some that can't be controlled. The sheer difficulty in designing a scientifically valid clinical study points out clearly the importance of this type of research. Dental laboratory research is necessary and important but clinical evaluation must follow these types of studies.

Clinical studies of dental materials are sorely lacking. How good is dental research, then, if two very important factors, the patient and operator variables, are left out? No matter how many claims are made for a product, if it does not work in the hands of the clinician, if it isn't compatible with the patient, if it possesses properties causing difficulty in clinical and laboratory procedures, it isn't a product desirable for the dental profession. It does not work. 


\section{BIBLIOGRAPHY}

Arstadt, T. "The Capsular Ligaments of the Temperomandibular Joint and Retrusion Facets of the Dentition in Relationship to Mandibular Movements," Akademisk Forlag, Os1o, 1954.

Berman, M. "Accurate Interocclusal Records," J Pros Dent., Vo1. 10, 1960.

Beyron, H.L. "Occlusal Relations and Mastication in Australian Aborigines," A.C.T.A. Odont. Scand., Vo1. 22, 1964, 597-678.

Beyron, H.L. "Optimal Occlusion," Dent. Clinics of North America, Vo1. 13, No. 3, Ju1y, 1969.

Brecker, S.C. "Conservative Occlusal Rehabilitation," J Pros Dent., Vo1. 9, No. 6, Nov-Dec., 1959, 1002.

Boucher, Carl. "Through the Eyes of the Editor," J Pros Dent., Vo1. 28, No. 4, October, 1972, 354.

Boucher, L.J. and Jacoby, J. "Posterior Border Movements of the Human Mandible," J Pros Dent., Vo1. 11, 1961, 836-841.

Brotman, Don. "Contemporary Concepts of Articulation," J Pros Dent., Vo1. 10, March-April, 1960.

Brotman, Don. "Hinge Axis. Part I. The Transverse Hinge Axis," I Pros Dent., Vo1. 10, May-June, 1960, 440.

Cohen, R. "The Hinge Axis and Its Practical Application in the Determination of Centric Relation," J Pros Dent., Vo1. 10, March-April, 1960.

Cohn, L.A. "The Factors of Dental Occlusion Pertinent to the Restorative and Prosthetic Problem," J Pros Dent., Vo1. 9, $1959,256-277$.

Combe, E.C. Notes on Dental Materials. 2nd Ed., ChurchillLivingston, 1975.

Coulourites, Alex. "Freeway Space," J Pros Dent., Vo1.5, March, 1955.

De Marco and Paine. "Mandibular Dimensional Change," J Pros Dent., $1974,428-485$. 
Docking, A.R. "Modern Materials in Dental Practice," Aust. Dent. J., Vo1. 15, 1970, 303-309.

Douglass, Gordon. "The Cast Restoration-Why is it High?" J Pros Dent., Vo1. 34, 1975, 491-495.

Frisch, J., Bhaskar, S.N., and Bales, D. "Clinical Study of Normal Occlusion (unpublished), 1966.

Goto. "An Experimental Study on the Physiologic Mobility of a Tooth," Shikwa Gakuho, Vo1. 71, 1971, 1415-1444.

Granger, E. "The Principles of Obtaining Occlusion in Occlusal Rehabilitation," J Pros Dent., Vo1. 13, 1963.

Guichet, N. "Biologic Laws Governing Functions of Muscles that Move the Mandible. Part IV. Degree of Jaw Separation and Potential for Maximum Jaw Separation, J Pros Dent., Vol. 38, No. 3, September, 1977, 305-306.

Hoe1, Paul. Elementary Statistics, Third Edition, New York, London, Sydney, Toronto: John Wiley and Sons, Inc., 1971.

Jankelson, Hoffman, and Hendron. "The Physiology of the Stomatognathic System" J.A.D.A., No. 46, 1953.

Kingery, R. "Maxillomandibular Relationship of Centric Relation," J Pros Dent., Vol. 9, Nov-Dec., 1959, 924-925.

Long, J.H. "Location of the Terminal Hinge Axis by Intraoral Means," J Pros Dent., Vol. 23, 1970.

Lyon, Douglas M. "The Establishment of Occlusion," Dental Clinics of North America, Nov. 1960.

Millstein, Clark, and Kronman. "Accuracy of Wax Interocclusal Registrations," J Pros Dent., Vo1. 29, 1973.

Moyers, R. "Some Physiologic Considerations of Centric and Other Jaw Relations," I Pros Dent., Vo1. No. 6, 1956.

Nagle, R.J. "Personal Communication to Martin Henry Berman," July 6, 1959.

Osborne, J. "Occlusion and Prosthetic Dentistry," Dental Clinics of North America, Vo1. 13, No. 3, Ju1y, 1969, 623.

Pameijer, J., Glickman, I., and Roeber, F.W. "Intraoral Occlusal Telemetry. II Registration of Tooth Contacts in Chewing and Swallowing," I Pros Dent., Vo1. 19, 1960, 151. 
Posselt, U. Physiology of Occlusion and Rehabilitation. Philadelphia: The F.A. Davis Co., 1962 .

Posselt, U. "Range of Movements of the Mandible," J.A.D.A., Vol. 56, $1958,10-13$.

Posselt, U. "An Analyzer for Mandibular Positions," J Pros Dent., Vol. 7, 1957, 368-374.

Ricketts, R.M. "Variations of the Temperomandibular Joint as Revealed by Cephalometric Laminography," Am J Orthodont., Vo1. 36, 1950, 877.

Schireson, S. "Grinding Teeth for Masticatory Efficiency and Gingival Health," J Pros Dent., Vol. 13, Mar-April, 1963, 344.

Schweitzer, J. "Dental Occlusion: A Pragmatic Approach," Dental Clinics of North America, Vol. 13, No. 3, Ju1y, 1969, $\overline{706-707}$.

Silverman, S.I. "Management of the Trial Denture Base," DentaI Clinics of North America, March, 1957, 231-243.

Sicher, H.L. "The Biologic Significance of Hinge Axis Determination," J Pros Dent., Vol. 6, 1956, 620.

Sicher, H.L. Oral Anatomy, 4th Ed., St. Louis: The C.V. Mosby Co., $1965,505-510$.

Sindledecker, L. "Effect of Different Centric Relation Checkbites on Condylar Position," Masters Dissertation, University of Michigan, 1978.

Tylman, S. "Methods of Recording Interrocclusal Relationships," Tylman's Theory and Practice of Fixed Prosthodontics, 7th Ed., St. Louis: C.V. Mosby Co., 1978. 
APPENDIX 
ROTATION AND DECLANATION IN DEGREES AND THE X AND Y MOVEMENT OF THE CENTER OF THE ARTICULATOR HINGE AXIS IN MILLIMETERS

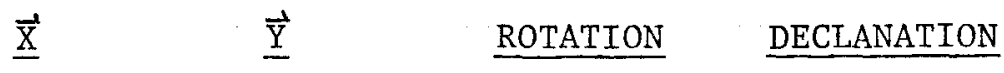

Pink Wax

Patient:

1

2

3

4

5

6

7

8

9

10

11

12

13

14

15

16

17

18

19

20

21

22

23

24

25

26

27

28

29

30

31

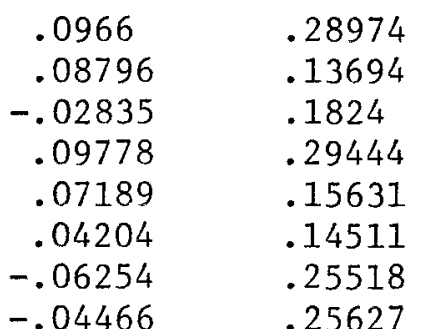

$-.04466 \quad .25627$

$-.1505$

$-.01201$

$-.13437$

$-.02939$

$-2.8 \times 10^{-4}$

.01567

$-.03318$

$-.1109$

$-.02398$

$-.13373$

.10557

.05335

.01785

.03038

$-6.9 \times 10^{-4}$

.03849

$6.43 \times 10$

.0582

.0281

.07287

$8.46 \times 10$

.17103

.07907
.37955

.15805

.15579

.13972

.17823

.20213

.22306

.14287

.16897

.15945

.14631

.18004

.28576

.38196

.1266

.38365

.20248

.16164

.18236

.17009

.33821

.31808

.25601
.2378
.2653
-.0692
.2305
.2141
-.5765
.0871
-.8985
.4711
-.5665
-.105
.5697

$-.2323$

$-.2297$

$-.6648$

1. 2635

.3861

.165

$-.4745$

$-.0787$

$-.2629$

$-.5862$

$-.5586$

$-.1817$

.3658

.3499

$8.6 \times 10^{-3}$

.0356

.5667

1. 209

.2209
.3106

.1046

$-.4786$

.2809

.6724

.0243

$-1.4693$

.4204

$-.1 .2122$

$-.1358$

.1748

$-.2552$

.0896

.2754

$-.8272$

$-.6452$

$-.3424$

.141

.2882

.536

.8907

.2321

$-.2083$

$-1.6136$

.3667

.1089

$-.4783$

.1887

$-1.1913$

1. 3676

$-.3201$ 


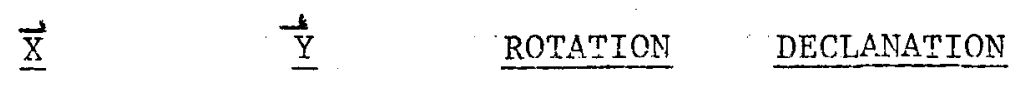

Reinforced Wax

Patient:

\begin{tabular}{|c|c|c|c|c|}
\hline 1 & .06296 & .12912 & .4146 & -.5485 \\
\hline 2 & -.07622 & .06713 & .4027 & -.1454 \\
\hline 3 & $5.4 \times 10^{-3}$ & .20562 & .2702 & .2958 \\
\hline 4 & .06301 & .12908 & .4149 & -.548 \\
\hline 5 & -.01591 & .20704 & -.2443 & .0366 \\
\hline 6 & .03656 & .15006 & -.0881 & .033 \\
\hline 7 & -.01037 & .20215 & -.3613 & -.0472 \\
\hline 8 & -.0783 & .15179 & .1996 & .0675 \\
\hline 9 & -.09987 & .13656 & -.2221 & -.0348 \\
\hline 10 & .04327 & .20695 & -.1 .12 .78 & .0682 \\
\hline 11 & .06828 & .42397 & -.2731 & .0949 \\
\hline 12 & -.0403 & .15912 & .1196 & -.4408 \\
\hline 13 & -.07296 & .20616 & -.0571 & -.0272 \\
\hline 14 & -.07288 & .15931 & .117 & .0357 \\
\hline 15 & -.14233 & .18125 & .5027 & .0685 \\
\hline 16 & -.07741 & .10499 & -.0929 & .1381 \\
\hline 17 & -.05113 & .09142 & -.0672 & $-3.2 \times 10^{-3}$ \\
\hline 18 & .03861 & .14698 & .0118 & -.1729 \\
\hline 19 & -.03789 & .06981 & -.4791 & -.0559 \\
\hline 20 & -.04572 & .08258 & -.4751 & .3978 \\
\hline 21 & -.06447 & .07702 & .3065 & -.0337 \\
\hline 22 & $3.16 \times 10^{-3}$ & .16871 & .1108 & .2551 \\
\hline 23 & -.05578 & .26009 & -.2808 & .4751 \\
\hline 24 & -.10415 & .15905 & -.1333 & .4004 \\
\hline 25 & -.01058 & .08794 & .0157 & .4501 \\
\hline 26 & -.03426 & .19234 & .0853 & .3374 \\
\hline 27 & .0949 & .24032 & .9756 & .2265 \\
\hline 28 & .02991 & .1043 & .197 & .6868 \\
\hline 29 & $-2.4 \times 10^{-3}$ & .12424 & -.1751 & -.24 .74 \\
\hline 30 & $-1.52 \times 10^{-3}$ & .31362 & -.5733 & .9355 \\
\hline 31 & .01888 & .17502 & -.41 .86 & -.1265 \\
\hline
\end{tabular}


$\underline{\vec{X}} \quad \underline{\vec{Y}} \quad$ ROTATION $\quad$ DECLANATION

Polyether With

Coe Tray

Patient:

\begin{tabular}{|c|c|c|c|c|}
\hline 1 & .05725 & .09343 & .0863 & -.0533 \\
\hline 2 & .0374 & .09033 & -.0548 & .0517 \\
\hline 3 & $-6.03 \times 10^{-3}$ & .07454 & .076 & -.0796 \\
\hline 4 & .06057 & .09906 & .0887 & -.0509 \\
\hline 5 & -.0317 & .09677 & -.3161 & .0852 \\
\hline 6 & $-6.45 \times 10^{-3}$ & .25309 & -.0817 & -.5773 \\
\hline 7 & -.04307 & .25817 & .5713 & -.9309 \\
\hline 8 & -.01602 & .07599 & -.1363 & .0848 \\
\hline 9 & -.05539 & .09097 & .0716 & -.0479 \\
\hline 10 & -.02251 & .03844 & -.2587 & .0162 \\
\hline 11 & -.0778 & .09654 & .1409 & -.0526 \\
\hline 12 & -.0196 & .07219 & -.164 & .0759 \\
\hline 13 & $3.16 \times 10^{-3}$ & .0915 & .05 & -.0652 \\
\hline 14 & $9 \times 10^{-4}$ & .09835 & .1966 & -.1464 \\
\hline 15 & 0.02231 & .10239 & -.0172 & .0367 \\
\hline 16 & -.0253 & .08457 & .0337 & .0961 \\
\hline 17 & $2.4 \times 10^{-4}$ & .031 & .1675 & -.2041 \\
\hline 18 & $-1.4 \times 10^{-4}$ & .05381 & -.2038 & $-2.3 \times 10^{-3}$ \\
\hline 19 & $4.5 \times 10^{-3}$ & -.20761 & .2349 & $-6.4 \times 10^{-3}$ \\
\hline 20 & .05358 & .09228 & .2509 & -.2231 \\
\hline 21 & $-7.27 \times 10^{-3}$ & .03029 & -.0479 & .1995 \\
\hline 22 & -.02635 & .03205 & -.0599 & .1223 \\
\hline 23 & $8.95 \times 10^{-3}$ & .20904 & .116 & .2882 \\
\hline 24 & $6.91 \times 10^{-3}$ & .07446 & -.1603 & -.3352 \\
\hline 25 & -.01172 & .10199 & .0667 & -.0685 \\
\hline 26 & .01876 & .10383 & .1879 & .3676 \\
\hline 27 & -.01791 & .07032 & -.181 & -.1368 \\
\hline 28 & -.04455 & .05171 & $-1.7 \times 10^{-3}$ & $5.10^{-3}$ \\
\hline 29 & -.06237 & .06584 & -.1426 & -.0992 \\
\hline 30 & $-5.64 \times 10^{-3}$ & .04492 & .0916 & .0683 \\
\hline 31 & -.05447 & .06325 & -.0769 & .0426 \\
\hline
\end{tabular}




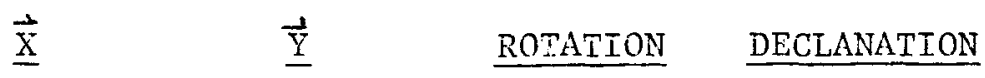

Polyether Without

Coe Tray

Patient:

\begin{tabular}{|c|c|c|c|c|}
\hline 1 & D & 0 & 0 & 0 \\
\hline 2 & .02024 & .05833 & .0331 & .1135 \\
\hline 3 & $9.42 \times 10^{-3}$ & .0181 & -.062 & -.11 .92 \\
\hline 4 & $3.67 \times 10^{-3}$ & .01981 & .0242 & .1305 \\
\hline 5 & 0 & 0 & 0 & 0 \\
\hline 6 & -.02367 & .02673 & .0358 & .0384 \\
\hline 7 & $1.99 \times 10^{-3}$ & .03607 & -.2429 & -.1022 \\
\hline 8 & -.0289 & .05109 & .1662 & .0579 \\
\hline 9 & -.01667 & .01105 & -.0896 & .0592 \\
\hline & 0 & 0 & 0 & 0 \\
\hline & -.0446 & .03741 & -.0133 & -.0762 \\
\hline & -.01341 & .02693 & -.0189 & -.0372 \\
\hline & $4.86 \times \mathrm{iO}^{-3}$ & .03249 & -.032 & -.214 \\
\hline & $-2.33 \times 10^{-3}$ & .02218 & .0154 & -.1461 \\
\hline & $-2.4 \times 10^{-4}$ & .02254 & -.0914 & -.0487 \\
\hline & -.01679 & .02234 & -.099 & .0816 \\
\hline & $-7.21 \times 10^{-3}$ & .02661 & $-1.7 \times 10^{-3}$ & .056 \\
\hline & $-8.42 \times 10^{-3}$ & .01137 & .0554 & -.0749 \\
\hline & -.01253 & .02789 & .0906 & $1.2 \times 10^{-3}$ \\
\hline & $9.87 \times 10^{-3}$ & .06132 & -.3372 & .0154 \\
\hline & $5.25 \times 10^{-3}$ & .05997 & -.1807 & -.1516 \\
\hline & $-9.97 \times 10^{-3}$ & .04701 & .0679 & -.0574 \\
\hline & .01767 & .09618 & -.1351 & -.097 \\
\hline & .0317 & .04092 & -.1269 & .0256 \\
\hline & -.03359 & .05009 & -.1112 & .1055 \\
\hline & -.0335 & .0295 & .0592 & .0174 \\
\hline & $-4.01 \times 10^{-3}$ & .02275 & .0264 & -.1498 \\
\hline & -.02097 & .06612 & .2505 & .1405 \\
\hline & $-3.81 \times 10^{-3}$ & .02405 & -.0251 & .1584 \\
\hline & $-3.74 \times 10^{-3}$ & .04925 & .0218 & $-6.3 \times 10^{-3}$ \\
\hline & $-9.01 \times 10^{-3}$ & $9.87 \times 10^{-3}$ & -.062 & .065 \\
\hline
\end{tabular}


$\underline{\overrightarrow{\mathrm{X}}} \quad \underline{\overrightarrow{\mathrm{Y}}} \quad \underline{\text { ROTATION }}$

ZOE

Patient:

\begin{tabular}{|c|c|c|c|c|}
\hline 1 & .04706 & .10448 & $7.9 \times 10^{-3}$ & $-6.5 \times 10^{-3}$ \\
\hline 2 & .01119 & .06221 & -.0347 & .1481 \\
\hline 3 & -.03152 & .07017 & .3249 & .0461 \\
\hline 4 & .05959 & .03262 & -.017 & -.0682 \\
\hline 5 & .04746 & .08792 & -.0426 & .1244 \\
\hline 6 & -.01664 & .15396 & -.1257 & .0928 \\
\hline 7 & -.01312 & .1218 & -.0353 & -.0333 \\
\hline 8 & -.01551 & .10906 & .1909 & -.0869 \\
\hline 9 & -.0248 & .10733 & .1918 & -.0548 \\
\hline 10 & $6.2 \times 10^{-4}$ & .10953 & -.23 & .2194 \\
\hline 11 & -.01528 & .13854 & .3352 & -.0665 \\
\hline 12 & -.06663 & .09729 & .1327 & -.0651 \\
\hline 13 & -.02712 & .17122 & -.0631 & .3984 \\
\hline 14 & -.02977 & .25162 & .5017 & -.6253 \\
\hline 15 & -.03829 & .14912 & .3212 & -.1935 \\
\hline 16 & $5.32 \times 10^{-3}$ & .13431 & -.1016 & .0681 \\
\hline 17 & -.01648 & .24713 & .1695 & -.2327 \\
\hline 18 & -.018 & .12494 & -.1351 & -.126 \\
\hline 19 & .01474 & .06134 & .2455 & .2141 \\
\hline 20 & -.02909 & .16587 & -.6476 & .6283 \\
\hline 21 & -.05147 & .08268 & -.0571 & .2676 \\
\hline 22 & $-.04215_{-3}$ & .08871 & -.223 & -.1091 \\
\hline 23 & $2.87 \times 10^{-3}$ & .10578 & -.2377 & .0922 \\
\hline 24 & $1.16 \times 10^{-3}$ & .04897 & -.2146 & .0432 \\
\hline 25 & -.05735 & .07782 & .1736 & -.3049 \\
\hline 26 & $1.88 \times 10^{-3}$ & .09711 & .1922 & .0513 \\
\hline 27 & -.0259 & .03698 & .1705 & -.2436 \\
\hline 28 & .01405 & .04595 & .0925 & .3026 \\
\hline 29 & $-5.58 \times 10^{-3}$ & .04944 & .0836 & -.1568 \\
\hline 30 & -.02211 & .03209 & -.2154 & .2113 \\
\hline 31 & -.01746 & .04085 & -.2006 & $5.3 \times 10^{-3}$ \\
\hline
\end{tabular}


ANGLES FORMED BY INTERSECTION OF LINES CO-CO' AND THE FRANKFORT HORIZONTAL PLANE

$* \theta=$ Angles enumerated +30

Right Condyle
Angle $\quad \begin{gathered}\text { Pink Wax } \\ \text { Left Condyle } \\ \text { Angle }\end{gathered}$

Patient:

1

2

3

4

5

6

7

8

9

10

11

12

13

14

15

16

17

18

19

20

21

22

23

24

25

26

27

28

29

30

31
76

68.5

94

76

54

47.5

99

64.5

111.5

67.5

132.5

123

78

72.5

79

141.5

110.5

139

30

56.5

69

71

62

84

108.5

88

84

64.5

98.5

96.5

81.5
68.5

50

109.5

68.5

68

107

147

119.5

112

125.5

129.5

60.5

100.5

94.5

144

29

73.5

121

80

81

93

98

132

85.5

76.5

58

75

68.5

59

56

61.5 


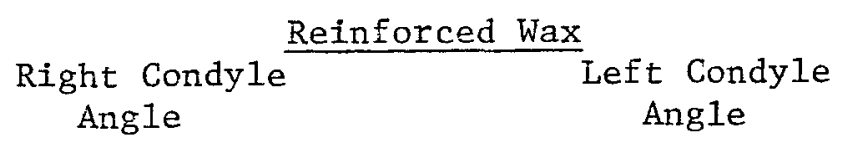

Patient:

1

2

3

4

5

6

7

8

9

10

11

12

13

14

15

16

17

18

19

20

21

22

23

24

25

26

27

28

29

30

31

90
147
102.5
90
84
71
78
127.5
115
42.5
75
104.5
107
120.5
142
127
114
78
66
40
143.5
96
94
130.5
123.5
103.5
104.5
0
81.5
63.5
67

20

108.5

79.5

20

104

81.5

108.5

106.5

135.5

120.5

86.5

103.5

112

108.5

109

126

124

71.5

151

129.5

104

84.5

106.5

119.5

93

95

48.5

74

108.5

101

106 


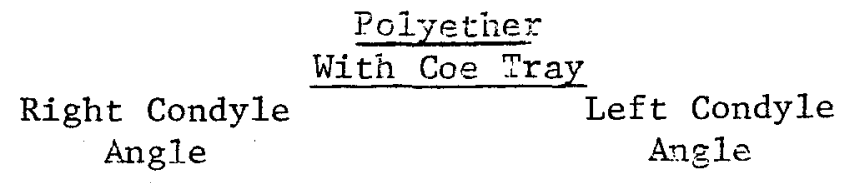

Patient:

1

2

3

4

5

6

7

8

9

10

11

12

13

14

15

16

17

18

19

20

21

22

23

24

25

26

27

28

29

30

31
66.5

61

101.5

66.5

79

89

108

79

124

65

133.5

85

92.5

103.5

101.5

113.5

112.5

62.5

98.5

83

0

142

93

76

101

101.5

84

131

117

119.5

127
50.5

73.5

85

50.5

3.26

96.5

69.5

116.5

118

146.5

122.5

118

82.5

68

103

101.5

0

118

79

32.5

103.5

125

84

126.5

91

73.5

132.5

130.5

149

81.5

133.5 


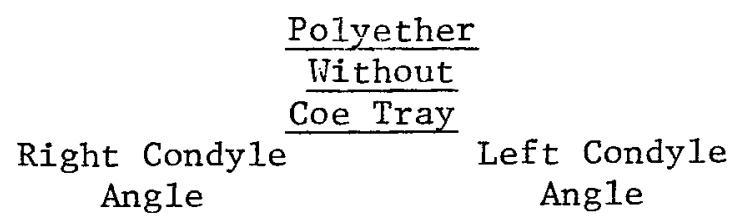

Patient:

\begin{tabular}{|c|c|c|}
\hline 1 & 0 & 79.5 \\
\hline 2 & 79.5 & 66.5 \\
\hline 3 & 62.5 & 0 \\
\hline 4 & 0 & 79.5 \\
\hline 5 & 0 & 0 \\
\hline 6 & 148.5 & 125.5 \\
\hline 7 & 53 & 149.5 \\
\hline 8 & 142 & 93.5 \\
\hline 9 & 146 & 146.5 \\
\hline 10 & 0 & 0 \\
\hline 11 & 131 & 151 \\
\hline 12 & 115.5 & 135 \\
\hline 13 & 81.5 & 0 \\
\hline 14 & 96 & 0 \\
\hline 15 & 65.5 & 133 \\
\hline 16 & 100 & 132.5 \\
\hline 17 & 111 & 102 \\
\hline 18 & 126.5 & 0 \\
\hline 19 & 133.5 & 87.5 \\
\hline 20 & 44 & 123 \\
\hline 21 & 68.5 & 121 \\
\hline 22 & 110 & 89.5 \\
\hline 23 & 71 & 92 \\
\hline 24 & 36 & 74.5 \\
\hline 25 & 122.5 & 130 \\
\hline 26 & 148.5 & 125.5 \\
\hline 27 & 100 & 0 \\
\hline 28 & 143.5 & 78 \\
\hline 29 & 0 & 99 \\
\hline 30 & 98 & 90.5 \\
\hline 31 & 0 & 133 \\
\hline
\end{tabular}




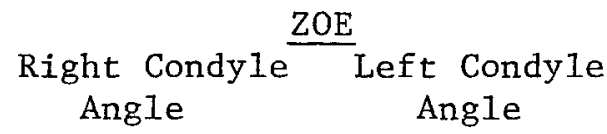

Patient:

\begin{tabular}{|c|c|c|}
\hline 1 & 66.5 & 65 \\
\hline 2 & 67.5 & 86 \\
\hline 3 & 142 & 77 \\
\hline 4 & 66.5 & 65 \\
\hline 5 & 52 & 69 \\
\hline 6 & 89 & 102 \\
\hline 7 & 93.5 & 99 \\
\hline 8 & 110 & 82 \\
\hline 9 & 115 & 87.5 \\
\hline 10 & 65 & 103.5 \\
\hline 11 & 114 & 74.5 \\
\hline 12 & 129 & 118 \\
\hline 13 & 99 & 99 \\
\hline 14 & 107 & 73.5 \\
\hline 15 & 116 & 85 \\
\hline 16 & 80.5 & 94 \\
\hline 17 & 98.5 & 87.5 \\
\hline 18 & 89 & 110 \\
\hline 19 & 128 & 61 \\
\hline 20 & 45.5 & 116 \\
\hline 21 & 135.5 & 116 \\
\hline 22 & 94.5 & 136.5 \\
\hline 23 & 67 & 105.5 \\
\hline 24 & 51.5 & 119.5 \\
\hline 25 & 124 & 134.5 \\
\hline 26 & 107 & 73.5 \\
\hline 27 & 125 & 0 \\
\hline 28 & 0 & 73 \\
\hline 29 & 104 & 74.5 \\
\hline 30 & 0 & 130.5 \\
\hline 31 & 72 & 139 \\
\hline
\end{tabular}


MEASUREMENT OF LINE CO-CO'

$\mathrm{CO}=\mathrm{Hand}$ Articulation

$\mathrm{CO}^{\prime}=$ Position with interocclusal record between casts

\begin{tabular}{|c|c|c|c|c|c|c|}
\hline \multirow[b]{2}{*}{ Patient } & \multicolumn{2}{|c|}{ ZOE } & \multicolumn{2}{|c|}{ Pink Wax } & \multicolumn{2}{|c|}{ Reinforced Wax } \\
\hline & Right & Left & Right & Left & Right & Lef $t$ \\
\hline 1 & .1150 & .1142 & .2500 & .3621 & .2124 & .1340 \\
\hline 2 & .0432 & .0849 & .1301 & .1995 & .1638 & .0475 \\
\hline 3 & .1026 & .0792 & .2557 & .1164 & .1646 & .2548 \\
\hline 4 & .1559 & .1349 & .2595 & .3623 & .2123 & .1341 \\
\hline 5 & .0876 & .1144 & .0670 & .2787 & .2026 & .2191 \\
\hline 6 & .1399 & .1718 & .1918 & .1556 & .1534 & .1568 \\
\hline 7 & .1271 & .1182 & .4843 & .0588 & .2140 & .2056 \\
\hline 8 & .1301 & .0968 & .2132 & .3678 & .1784 & .1690 \\
\hline 9 & .1276 & .0991 & .6058 & .2108 & .1565 & .1873 \\
\hline 10 & .0841 & .1469 & .1934 & .1688 & .2910 & .2522 \\
\hline 11 & .1627 & .1333 & .1753 & .2366 & .4240 & .4392 \\
\hline 12 & .1379 & .0990 & .2128 & .1160 & .2335 & .1173 \\
\hline 13 & .1121 & .2346 & .1683 & .1951 & .2199 & .2179 \\
\hline 14 & .3624 & .1634 & .1681 & .2447 & .1786 & .1737 \\
\hline 15 & .1986 & .0202 & .3552 & .1658 & .2775 & .2027 \\
\hline 16 & .1257 & .1450 & .3869 & .0926 & .1052 & .1557 \\
\hline 17 & .2856 & .2120 & .2359 & .1220 & .1006 & .1097 \\
\hline 18 & .1441 & .1126 & .2104 & .2110 & .1771 & .1273 \\
\hline 19 & .0366 & .1073 & .2051 & .1930 & .0857 & .1265 \\
\hline 20 & .0988 & .2907 & .1183 & .2647 & .0345 & .1853 \\
\hline 21 & .0600 & .1372 & .1612 & .4216 & .1381 & .0741 \\
\hline 22 & .1056 & .1048 & .3667 & .4213 & .1307 & .2084 \\
\hline 23 & .0997 & .1243 & .1792 & .1278 & .1884 & .2542 \\
\hline 24 & .0542 & .0638 & .6322 & .1390 & .1292 & .2526 \\
\hline 25 & .1497 & .0442 & .1548 & .2655 & .0235 & .1565 \\
\hline 26 & .0934 & .1094 & .1452 & .2101 & .1488 & .2445 \\
\hline 27 & .0903 & .0000 & .2564 & .1136 & .2127 & .3668 \\
\hline 28 & .0000 & .0961 & .1567 & .2136 & .0000 & .2170 \\
\hline 29 & .0755 & .0266 & .5249 & .1835 & .1636 & .0914 \\
\hline 30 & .0106 & .0844 & .1111 & .6342 & .1917 & .0462 \\
\hline 31 & .0421 & 0635 & .3080 & .2360 & .2110 & .1621 \\
\hline
\end{tabular}

Al1 figures are in centimeters 


\begin{tabular}{|c|c|c|c|c|}
\hline Patient: & P With & Coe Tray & P Without & Coe Tray \\
\hline 1 & .1107 & .1106 & .0000 & .0403 \\
\hline 2 & .0943 & .1024 & .0418 & .0824 \\
\hline 3 & .0884 & .0627 & .0408 & .0000 \\
\hline 4 & .1181 & .1164 & .0000 & .0403 \\
\hline 5 & .0854 & .1356 & .0000 & .0000 \\
\hline 6 & .1181 & .1164 & .0000 & .0403 \\
\hline 7 & .4201 & .1247 & .0646 & .0405 \\
\hline 8 & .0643 & .0993 & .0687 & .0600 \\
\hline 9 & .1185 & .0948 & .0037 & .0363 \\
\hline 10 & .0397 & .0741 & .0000 & .0000 \\
\hline 11 & .1441 & .1050 & .0649 & .0533 \\
\hline 12 & .0609 & .0948 & .0361 & .0301 \\
\hline 13 & .1015 & .0823 & .0657 & .0000 \\
\hline 14 & .1240 & .0821 & .0446 & .0000 \\
\hline 15 & .0988 & .1108 & .0329 & .0207 \\
\hline 16 & .0763 & .1012 & .0471 & .0101 \\
\hline 17 & .0671 & .0252 & .0194 & .0359 \\
\hline 18 & .0667 & .0662 & .0283 & .0000 \\
\hline 19 & .2109 & .2105 & .0382 & .0281 \\
\hline 20 & .1271 & .1087 & .0849 & .0759 \\
\hline 21 & .0000 & .0623 & .0892 & .0431 \\
\hline 22 & .0219 & .0318 & .0593 & .0383 \\
\hline 23 & .1655 & .2542 & .1173 & .0815 \\
\hline 24 & .1292 & .0293 & .0630 & .0465 \\
\hline 25 & .1145 & .0916 & .0404 & .0863 \\
\hline 26 & .0490 & .1665 & .0516 & .0396 \\
\hline 27 . & .0916 & .0672 & .0462 & .0000 \\
\hline 28 & .0675 & .0690 & .0753 & .0894 \\
\hline 29 & .0908 & .0986 & .0000 & .0487 \\
\hline 30 & .0397 & .0559 & .0507 & .0483 \\
\hline 31 & .0711 & .0961 & .0004 & .0270 \\
\hline
\end{tabular}

A11 figures are in centimeters. 


\section{APPROVAL SHEET}

The thesis submitted by LaDeane Fattore-Bruno has been read and approved by:

Doctor William F. Malone

Doctor Boleslaw Mazur

Doctor James L. Sandrik

The final copies have been examined by the director of the thesis committee and the signature which appears below verifies the fact that any necessary changes have been incorporated, and that the thesis is now given final approval with reference to content, form and mechanical accuracy.

The thesis is therefore accepted in partial fulfillment of the requirements for the Degree of Master of Science.
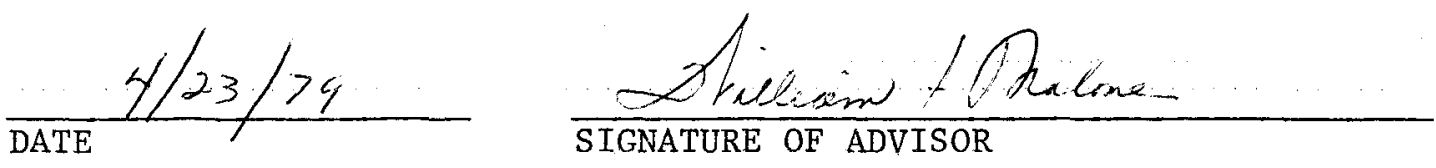